\author{
UNIVERSIDADE DE SÃO PAULO \\ FACULDADE DE ECONOMIA, ADMINISTRAÇÃO E CONTABILIDADE \\ DEPARTAMENTO DE ECONOMIA \\ PROGRAMA DE PÓS-GRADUAÇÃO EM ECONOMIA
}

\title{
Os impactos do Mercosul sobre o comércio: uma abordagem gravitacional
}

Bruno Ferreira Cordeiro

Orientador: Prof. Dr. Mauro Rodrigues Júnior

São Paulo

2016 
Prof. Dr. Marco Antonio Zago

Reitor da Universidade de São Paulo

Prof. Dr. Adalberto Américo Fischmann

Diretor da Faculdade de Economia, Administração e Contabilidade

Prof. Dr. Hélio Nogueira da Cruz

Chefe do Departamento de Economia

Prof. Dr. Márcio Issao Nakane

Coordenador do Programa de Pós-Graduação em Economia 


\title{
BRUNO FERREIRA CORDEIRO
}

\section{Os impactos do Mercosul sobre o comércio: uma abordagem gravitacional}

\begin{abstract}
Dissertação apresentada ao Programa de Pós-Graduação em Economia do Departamento de Economia da Faculdade de Economia, Administração e Contabilidade da Universidade de São Paulo como requisito parcial para a obtenção do título de Mestre em Ciências.
\end{abstract}

Orientador: Prof. Dr. Mauro Rodrigues Júnior

\section{Versão Corrigida}

\section{São Paulo}


FICHA CATALOGRÁFICA

Elaborada pela Seção de Processamento Técnico do SBD/FEA/USP

Cordeiro, Bruno Ferreira

Os impactos do Mercosul sobre o comércio: uma abordagem gravitacional / Bruno Ferreira Cordeiro. - São Paulo, 2016.

$58 \mathrm{p}$.

Dissertação (Mestrado) - Universidade de São Paulo, 2016.

Orientador: Mauro Rodrigues Júnior.

1. Comércio 2. Economia internacional 3. Acordos comerciais I. Universidade de São Paulo. Faculdade de Economia, Administração e Contabilidade. II. Título.

CDD -380.1 


\section{Agradecimentos}

Gostaria de agradecer a Deus, em primeiro lugar, por ter me dado saúde e perseverança durante todo o mestrado. Aos meus pais, Toninho e Cida, e à minha irmã Paôla pelo apoio e companheirismo durante esta jornada. Ao meu orientador Mauro pela ajuda na realização deste trabalho. Ao pessoal do BID, em especial ao Mauricio, André, Cecilia e Kun pelos conselhos e por terem me acolhido tão bem. Por fim, também sou muito grato ao apoio financeiro recebido sob o processo n ${ }^{\circ}$ 2014/19354-0, Fundação de Amparo à Pesquisa do Estado de São Paulo (FAPESP). 


\section{Resumo}

Esta dissertação tem como objetivo medir os efeitos do Mercosul em termos de criação, desvio de comércio e desvio de exportação, usando uma base de dados abrangente e o que há de mais moderno na literatura de gravidade. Nos últimos anos, houve um grande avanço tanto na teoria quanto na estimação de equações de gravidade, o que ajudou na microfundamentação destes modelos e na obtenção de resultados consistentes. As estimações feitas mostram que o bloco possibilitou uma criação de comércio, o que ocorre quando tanto o comércio realizado intra bloco quanto com o resto do mundo aumentam. Além do mais, foram estimados modelos com a finalidade de verificar como os efeitos do Mercosul sobre comércio evoluíram ao longo dos anos, mostrando que o efeito maior do bloco se deu nos anos 90. Outra importante questão analisada foi o impacto do Mercosul sobre dois setores econômicos: agricultura e indústria. Nestes setores também houve indícios de criação de comércio, no entanto a indústria presenciou desvio de exportações em direção ao bloco. Por fim, foram construídos alguns grupos contrafactuais, que indicam que na ausência deste acordo o comércio teria sido menor, apesar dos efeitos serem heterogêneos entre os anos e os países.

Palavras-chaves: Comércio. Economia Internacional. Acordos comerciais. 


\section{Abstract}

This dissertation aims to measure the effects of Mercosur in terms of trade creation and diversion and export diversion, using a comprehensive database and the most modern instruments in gravity literature. In recent years, there has been a great advancement in theory and estimation of gravity equations, which helped the microfoundation of these models and the obtainment of consistent results. Our estimates show that Mercosur resulted in trade creation, which occurs when both the intra regional trade and trade with the rest of the world increase. Moreover, we estimated some models in order to see how the effects of Mercosur on trade has evolved over the years, showing that the greatest effects occurred in the 90's. Another important issue discussed was the impact of Mercosur on two economic sectors: agriculture and industry. In these sectors there was also evidence of trade creation, however industry has suffered exports diversion towards the block. Finally, we constructed some contrafactual groups, which indicate that in the absence of Mercosur trade would be smaller, although the effects are heterogeneous across years and countries.

Key-words: Trade. International Economics. Trade Agreements. 


\section{Sumário}

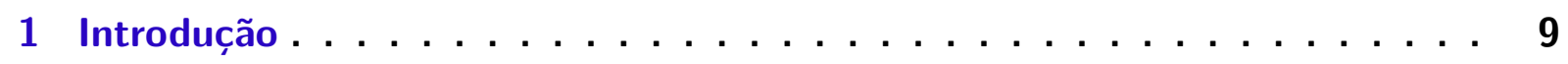

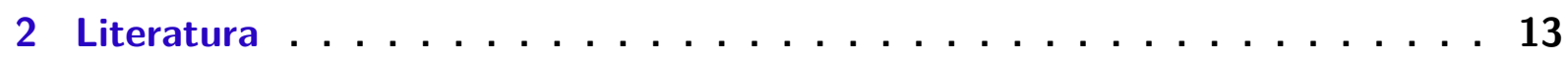

2.1 História do Mercosul . . . . . . . . . . . . . . . . . . . . . . 13

2.2 Custos e benefícios de um acordo comercial . . . . . . . . . . . . . 14

2.3 Impactos de acordos comerciais e do Mercosul . . . . . . . . . . . . 17

2.4 Outros aspectos sobre acordos comerciais e Mercosul _ . . . . . . . . . 19

3 Metodologia ....................... 23

3.1 Base de dados . . . . . . . . . . . . . . . . . . . . . 28

4 Resultados. . . . . . . . . . . . . . . . . . . 31

4.1 Evolução do comércio . . . . . . . . . . . . . . . . . . . . . . . . 31

4.2 Efeitos do Mercosul . . . . . . . . . . . . . . . . . . . . . . 33

4.3 Dinâmica do Mercosul . . . . . . . . . . . . . . . . . . . . 37

4.4 Contrafactual . . . . . . . . . . . . . . . . . . . 40

4.5 Estimações setoriais . . . . . . . . . . . . . . . . . . . 43

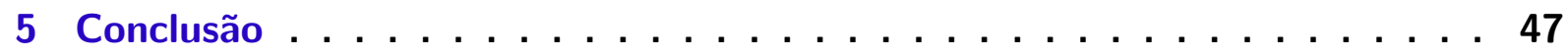

Referências . . . . . . . . . . . . . . . . . 49

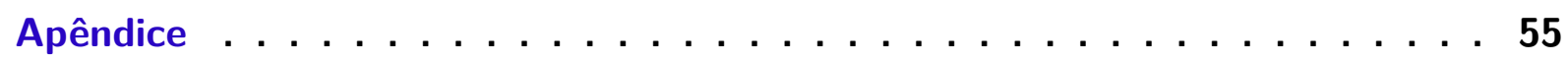




\section{Introdução}

O Mercado Comum do Sul (Mercosul) foi criado em 1991 por Argentina, Brasil, Paraguai e Uruguai com o objetivo de implementar uma união aduaneira e facilitar o livre comércio entre eles, em meio ao processo conhecido como Novo Regionalismo pelo qual passava a América Latina, cujo resultado foi a adoção de acordos sub regionais de comércio (DeVlin; ESTEVAdeORDAL, 2001). Passados quase 25 anos da criação do Mercosul, a pergunta natural que surge diz respeito ao impacto dele sobre o comércio tanto dos países que o compõe quanto com os de fora do bloco.

O objetivo desta dissertação é avaliar se o Mercosul resultou em criação ou desvio de comércio e se houve desvio de exportações, fazendo uso de uma base de dados abrangente e do que há de mais moderno no instrumental da literatura de gravidade. Os resultados obtidos são robustos a diferentes tipos de modelos e estimadores, e indicam que o bloco propiciou criação de comércio, ou seja, tanto as transações intra bloco quanto com o resto do mundo aumentaram. Acordos comerciais são criticados por alguns por supostamente desviar comércio, pois discriminariam os produtos de países de fora do acordo. No entanto, os resultados obtidos não corroboram essa crítica com relação ao Mercosul.

Além do mais, foram estimados modelos que verificam como o impacto do Mercosul sobre o comércio evoluiu ao longo do tempo, mostrando que o efeito do bloco foi maior nos anos 90 e começo da década passada, e vem caindo desde então. Posteriormente, foram construídos alguns grupos contrafactuais com o propósito de examinar o que teria ocorrido com o comércio caso o Mercosul não tivesse sido criado, indicando que as importações do resto do mundo seriam menores nos anos 90, enquanto as importações intra bloco seriam menores na década passada. Por fim, dois modelos gravitacionais foram usados para avaliarmos o impacto do Mercosul sobre agricultura e indústria. Nos dois setores houve evidências de criação de comércio, no entanto também houve desvio de exportações na indústria.

De modo geral, este trabalho contribui com a literatura em três direções. Em primeiro lugar, grande parte dos trabalhos foram feitos na década de 90 e começo dos anos 
2000, o que seria insuficiente para capturar os efeitos dinâmicos tão importantes em termos de acordos comerciais. Em segundo lugar, poucos trabalhos nessa área se utilizam do instrumental de gravidade para estudar efeitos setoriais, de acordo com meu conhecimento. A maioria dos estudos setoriais se utiliza de estatísticas descritivas e índices, como os de vantagem comparativa e direcionamento de exportações. Em último lugar, este trabalho se utiliza da metodologia mais moderna de gravidade, como o estimador de Poisson Pseudo Maximum Likelihood (PPML), em conjunto com diferentes estimadores e efeitos fixos, para estimar a equação de gravidade tanto na forma multiplicativa quanto na log linearizada, garantindo robustez aos resultados.

A literatura de gravidade tem evoluído bastante ao longo da última década. Pelo lado teórico, o artigo de Anderson e Wincoop (2001) mostrou a importância dos termos multilaterais de resistência para a correção de viés de variável omitida. Basicamente, estes termos ajudam a controlar por custos de transação de um determinado país em relação a todos os seus parceiros comerciais. Pelo lado da estimação, Silva e Tenreyro (2006) e Silva e Tenreyro (2010) evidenciam como os estimadores de Poisson ajudam a corrigir os problemas de heterocedasticidade e da grande quantidade de zeros que se perde de informação quando se usa a equação de gravidade na forma log linear. A grande vantagem destes estimadores está no fato de estimar esta equação em nível, permitindo maior uso de informação e estimações consistentes.

A literatura correlata a esta dissertação é aquela que estuda ex post os impactos de um acordo comercial sobre os fluxos de comércio utilizando a metodologia de gravidade. Com relação ao Mercosul, diversos artigos encontraram indícios de criação de comércio (MAGEE, 2008; SOLOAGA; WINTERSB, 2001; EICHER; HENN; PAPAGEORGIOU, 2012). Reis, Azevedo e Lélis (2014) também encontraram essas evidências, no entanto também obtêm efeitos de desvio de exportação. Em relação a produtos agrícolas, Nonnenberg e Mendonça (1999) usam um modelo de equilíbrio parcial e concluem que o bloco ajudou a criar comércio para seis produtos agrícolas brasileiros: trigo, algodão, arroz, bovino, leite e milho. No nosso trabalho, encontramos criação de comércio para as importações agrícolas totais. Por fim, Yeats (1998) usa índices de vantagem comparativa e direcionamento de 
exportações e encontra que os países do bloco aumentaram suas exportações em direção aos parceiros de produtos em que não possuíam vantagem comparativa. Resultado semelhante ao que encontramos, de desvio de exportações, apesar de que encontramos criação de comércio relativo às importações de produtos manufaturados.

O restante da dissertação está dividido da seguinte maneira. No capítulo 2 será feita uma revisão de literatura, na qual será contada a história do Mercosul, discutido os custos e benefícios de acordos comerciais e revisado o que foi estudado sobre Mercosul e blocos comerciais em geral. No capítulo 3 será explicada a metodologia utilizada e será feita uma breve resenha da literatura de gravidade. O capítulo 4 mostra os resultados obtidos divididos em cinco subseções. A primeira traz a evolução do comércio interno do Mercosul e das trocas deste com o resto do mundo. A segunda reporta as estimações de modelos para checar se houve criação ou desvio de comércio e desvio de exportação, enquanto na terceira são estimados alguns modelos para verificarmos como os efeitos do Mercosul sobre o comércio evoluíram ao longo dos anos. A subseção quatro faz um exercício de contrafactual para comparar o que teríamos de comércio caso não tivesse sido criado o Mercosul. A última subseção mostra duas estimações setoriais: um para a agricultura e outro para a indústria. Por fim, as conclusões encerram a dissertação. 



\section{Literatura}

\subsection{História do Mercosul}

O fim dos anos 80 e início dos 90 foi um período de intensas transformações na América Latina. Depois de passar por uma década marcada por crises de dívida externa e baixo crescimento econômico, os países da região implementaram diversas reformas econômicas pró mercado e se juntaram na criação de cinco blocos comerciais subregionais (Comunidade Andina, Mercado Comum Centro Americano, Associação de Livre Comércio Caribenha, Mercado Comum do Sul (Mercosul) e Associação de Livre Comércio Norte Americana (Nafta)), dando início ao processo que ficou conhecido como Novo Regionalismo. 1

Em 1988, as duas maiores economias sul americanas (Brasil e Argentina) assinaram um acordo de cooperação econômica com o intuito de eliminar todas as barreiras ao comércio entre os dois países em um período de 10 anos. $^{2}$ Com o avanço nas negociações, outros dois países da região (Paraguai e Uruguai) também foram atraídos para o acordo comercial, o que culminou com a criação do Mercosul em março de 1991.

Com a assinatura do Tratado de Assunção, o Mercosul foi criado por Argentina, Brasil, Paraguai e Uruguai. Entre os principais objetivos dessa união aduaneira estão a redução progressiva, linear e automática das tarifas, além da eliminação de barreiras não tarifárias e o estabelecimento de uma tarifa externa comum (CET). O cronograma estabelecido previa reduções tarifárias semestrais, com o término previsto para dezembro de 1994. "Este novo acordo estava em contraste profundo com o tratado de integração regional assinado em 1988, no qual reduções em tarifas eram gradualmente negociadas setor por setor e o livre comércio seria alcançado em dez anos". (BUSTOS, 2011, p. 316)

Apesar das intenções de se eliminar as barreiras ao comércio interno ao bloco, algumas exceções foram permitidas, como os regimes especiais para açúcar e automóveis

1 Para maiores informações sobre o Novo Regionalismo, ver Devlin e Estevadeordal (2001).

2 Behar (1991) explica em detalhes o acordo. 
por exemplo. Além do mais, alguns produtos tinham tarifas diferentes da CET. Mas de modo geral, as reformas unilaterais tomadas pelos países e a implementação do bloco permitiram uma queda acentuada nas tarifas. ${ }^{3}$ Em 1989, a Argentina tinha uma tarifa média de 30\%, enquanto o Brasil tinha uma de 51\% em 1988 e o Uruguai de mais de $100 \%$ em 1978. Já em 1995, a CET média cobrada pelos países do bloco era de 10,7\%.

O Tratado de Assunção foi complementado com a assinatura do Protocolo de Ouro Preto em dezembro de 1994. Esse protocolo tinha o objetivo de completar o processo de formação da união aduaneira, tratando de questões institucionais como resolução de conflitos entre os países membros, e dando um aspecto legal em âmbito internacional ao bloco. Os governos haviam negociado uma CET para todos os produtos mas implementaram somente 75\% das linhas totais tarifárias em 1995 (OLARREAGA; SOLOAGA, 1998). Para os $25 \%$ restantes, foi permitido um período de transição para que a CET convergisse, sendo 2001 o fim do prazo para Brasil e Argentina e 2006 para Paraguai e Uruguai. Novamente, havia exceções para produtos sobre os quais não houve acordo.

\subsection{Custos e benefícios de um acordo comercial}

O principal benefício obtido com a assinatura de um acordo comercial é a criação de comércio, decorrente de uma queda nas tarifas alfandegárias. Este termo indica um aumento nas transações comerciais entre dois parceiros em função da assinatura de um acordo preferencial de comércio (PTA) entre eles. No entanto, as médias das tarifas Most Favored Nation (MFN) se encontram em um patamar baixo, enquanto muitos PTAs continuam sendo criados. Por isso, Limão (2016) aponta que outros fatores importantes ajudam a explicar os grandes efeitos agregados sobre o comércio provenientes destes acordos, como a eliminação de barreiras não-tarifárias e a diminuição da incerteza em relação a políticas futuras. "As evidências sugerem que certos PTAs podem, crivelmente, assegurar acesso de mercado relativo ao obtido no contexto da Organização Mundial do Comércio (OMC) e assim servir como seguro contra guerras comerciais durante grandes

$\overline{3}$ Laird (1997) faz uma discussão detalhada dos objetivos e do que foi alcançado pelo Mercosul. 
crises" (LIMãO, 2016, p. 2).

Além do motivo tradicional que incentiva o surgimento de acordos comerciais, há outros não-tradicionais, de cunho econômico ou não-econômico. No primeiro caso, há o incentivo ao investimento estrangeiro direto e difusão tecnológica, enquanto no segundo caso há políticas de proteção ao meio ambiente, direitos humanos, resolução de conflitos e promoção da democracia (LIMãO, 2016). No entanto, esses fatores ainda foram pouco explorados na literatura.

Os principais custos associados a PTAs são o desvio de comércio e desvio de exportação, que podem ocorrer em acordos não planejados corretamente, possibilitando inclusive uma perda de bem estar agregada, mesmo na ocorrência de criação de comércio. Desvio de comércio ocorre quando há uma diminuição das importações oriundas de fora do bloco comercial, em favor das importações vindas dos parceiros beneficiados com reduções tarifárias. Se os países de fora forem os produtores mais eficientes (custo mais baixo), há perda de bem estar para os consumidores dos países do bloco. Desvio de exportação significa um direcionamento das exportações de um país pertencente a um PTA aos seus parceiros comerciais, em detrimento dos países de fora. Neste caso, a possível perda de bem estar será sofrida pelos consumidores de fora do bloco.

Venables (2002) argumenta que acordos Sul-Sul costumam ter benefícios bem modestos, oriundos principalmente de efeitos de escala. Além do mais, nestes acordos haveria uma maior propensão à divergência de renda entre os países do bloco, com o país de vantagem comparativa extrema sofrendo queda na renda e bem estar, e com o país de vantagem intermediária em relação ao bloco e resto do mundo se beneficiando. Já em acordos Norte-Norte haveria uma convergência de renda entre os países, pois nesse caso o país de vantagem extrema que tenderia a perder mais com o bloco seria o mais rico (ou com dotação melhor). Posto isso, países em desenvolvimento ganhariam mais com acordos Norte-Sul em comparação a acordos Sul-Sul, pois naqueles o incremento no comércio seguiria as vantagens comparativas dos membros. ${ }^{4}$

4 Venables (2003) explica estas questões em um contexto mais formal, usando três modelos: uma análise de diagrama com dois bens, um modelo de comércio Ricardiano com múltiplos bens e um modelo 
Partindo do clássico estudo de Viner (1950) sobre criação e desvio de comércio, a teoria mostra que uma diminuição multilateral de tarifas aumenta o bem estar, enquanto o efeito de uma diminuição preferencial é incerto. ${ }^{5} \mathrm{O}$ motivo é que além da criação de comércio intra bloco, este tipo de corte de tarifa pode deslocar importações dos fornecedores de menor custo para outros de maior custo entre os parceiros do bloco cujas exportações têm tratamento preferencial (VENABLES, 2002). O Mercosul é um bom exemplo de bloco em que esses efeitos perversos poderiam ocorrer. Seus membros são países em desenvolvimento e não possuem vantagem comparativa na produção de bens industriais em relação ao resto do mundo, ou seja, um aumento no comércio intra bloco destes bens poderia resultar em perda de bem estar. Além do mais, o que se viu no Mercosul na última década foi um retrocesso interno com a tomada de medidas protecionistas, principalmente pelo governo Argentino, como barreiras não tarifárias e impostos sobre exportações.

Apesar do protecionismo e de possíveis problemas relacionados a desvio de comércio, Moreira (2003) argumenta que o Mercosul foi concebido como um instrumento de facilitação da integração dos países do bloco à economia mundial. Portanto, o bloco não era visto como alternativa à integração mundial, mas sim como uma estratégia para maximizar os benefícios da mesma. Os argumentos econômicos para a formação do bloco vão em três direções, basicamente. $\mathrm{O}$ primeiro se refere às economias de escala, pois um mercado maior ajudaria as firmas a competirem em melhores condições no restante do mundo. O segundo argumento aponta a maior rapidez em direção ao livre comércio comparado às negociações multilaterais. O bloco envolve poucos países, o que evitaria custos de ajustamento de acesso a mercados assimétricos em uma liberalização unilateral, enquanto o multilateralismo costuma ser complexo e muito moroso. Por fim, o bloco possibilitaria um maior poder de barganha dos países membros em negociações regionais e multilaterais.

Por outro lado, Moreira (2003) também discute os riscos e limitações inerentes a acordos comerciais Sul-Sul. Existem dois problemas principais com estes. O primeiro se refere aos efeitos de escala, pois mesmo que estes acordos sejam feitos com o objetivo de

Heckscher-Olin com dois fatores e dois setores do tipo Armington.

5 Krishna (2013) discute os argumentos relativos ao mérito de PTAs e os recentes desenvolvimentos no comércio internacional sob uma perspectiva multilateralista. 
superarem as desvantagens de mercados pequenos, geralmente o mercado expandido obtido pós acordo não atingirá os requisitos mínimos de escala em indústrias de capital intensivo. O segundo problema se refere às similaridades de fatores de produção e tecnologia entre os países membros, o que leva muitas vezes à sobreposição nas vantagens comparativas entre os mesmos, possibilitando o problema de desvio de comércio.

\subsection{Impactos de acordos comerciais e do Mercosul}

O Mercosul foi e continua sendo avaliado em diversos aspectos, seja através de seu impacto sobre o comércio da região ou pelos efeitos sobre a produtividade das firmas, por exemplo. Blocos econômicos em geral, como o Nafta e a União Europeia, são muito analisados dadas as potenciais consequências econômicas e políticas que eles podem acarretar. Além do mais, diversos artigos já estimaram os impactos de possíveis acordos comerciais ainda não existentes, como a Área de Livre Comércio das Américas (Alca) e o acordo de livre comércio entre Mercosul e União Europeia. ${ }^{6}$

Uma possível questão relacionada ao Mercosul seria seus efeitos em termos de comércio e bem estar. Diao e Somwaru (2000), Azevedo (2008) usam um modelo global de equilíbrio geral computável (CGE) para responder essa questão, medindo o que o bloco trouxe de comércio e bem estar tanto para os países membros quanto não membros. Na simulação dos primeiros, o bloco aumenta o bem estar dos membros estimulando investimento, produção e consumo, enquanto o segundo artigo acha um efeito pequeno. ${ }^{7}$ Já Behar (1995) usa um modelo de equilíbrio parcial para investigar a redução recíproca de tarifas por Argentina, Brasil e Uruguai. Apesar de todas as restrições inerentes a este tipo de modelo, os resultados mostram que o comércio intra bloco aumentaria bastante com a extinção das tarifas. Por outro lado, em termos de produto e bem estar, o Uruguai teria uma piora, enquanto Brasil e Argentina teriam ganhos.

6 Harrison et al. (2003), Gurgel, Bitencourt e Teixeira (2002) analisam os impactos da Alca e do acordo entre União Europeia e Mercosul, enquanto Kume et al. (2004), Negri e Arbache (2003), Alvim e Waquil (2005) estudam somente este último.

7 Outros blocos também foram estudados teoricamente com o uso de modelos CGE (FRANCOIS; SHIELLS, 2008; ADAMS, 1995). Para uma revisão de literatura sobre o uso de CGEs para analisar PTAs, ver Robinson e Thierfelder (2002). 
A literatura correlata a esta dissertação é aquela que estuda ex post os impactos de um acordo comercial sobre os fluxos de comércio utilizando a metodologia de gravidade. ${ }^{8}$ Com relação ao Mercosul, Freund e McLaren (1999) e Magee (2008) encontram efeitos antecipatórios decorrentes da criação do bloco, ou seja, o padrão de comércio dos países signatários começaram a se alterar alguns anos antes da assinatura do acordo. Já Soloaga e Wintersb (2001) estimam um modelo gravitacional com dados de 1980 a 1996 e acham um efeito significativo para o comércio intra bloco, além de indicarem uma tendência positiva para as importações em geral. ${ }^{9}$ Reis, Azevedo e Lélis (2014) encontram indícios de criação de comércio e desvio de exportação para o Mercosul no período entre 1990 e 2009, e também apontam efeito antecipação e criação de comércio para o Nafta. Por outro lado, Morais et al. (2006) usam dados de 1980 a 2002 e não encontram criação de comércio tanto no Mercosul quanto no Nafta. Martínez-Zarzoso e Nowak-Lehmann (2003) vão além e estimam os possíveis impactos sobre o comércio que um acordo entre Mercosul e União Europeia poderia trazer, e encontram que esses impactos seriam positivos. No entanto, esse estudo não faz diferenciação entre criação e desvio de comércio.

Os artigos citados até agora usam métodos usuais (OLS e efeitos fixos por exemplo) para estimar os modelos de gravidade e medir os impactos dos acordos comerciais. No entanto, recentemente surgiram alguns estudos que utilizam metodologias alternativas. Por exemplo, Eicher, Henn e Papageorgiou (2012) usam o método Bayesian model averaging (BMA) para medir os efeitos de criação e desvio de comércio para diversos PTAs. Eles encontram efeitos fortes e robustos a diversas especificações. Já Ghosh e Yamarik (2004a) usam o método de extreme bound analysis para testar se os PTAs são criadores de comércio, e encontram resultados frágeis para a maioria dos acordos. Em comum, essas duas metodologias têm a vantagem de incorporar à estimação a incerteza relativa ao modelo verdadeiro usando informações a priori, já que não há consenso na literatura sobre o correto conjunto de variáveis explicativas. No entanto, são metodologias ainda pouco utilizadas na área de comércio e gravidade.

8 A literatura nessa área é bem extensa. Para maiores detalhes, ver Carrere (2006), Piani e Kume (2000), Azevedo (2004), Cernat (2001), Ghosh e Yamarik (2004b), Porto e Canuto (2004).

9 Metodologia semelhante é empregada por Krueger (1999) para avaliar os impactos do Nafta. 
Para o caso brasileiro, Nonnenberg e Mendonça (1999) usam um modelo de equilíbrio parcial desenvolvido pela Unctad e Banco Mundial para calcular os efeitos de criação e desvio de comércio causados pelo Mercosul sobre os seis principais produtos agrícolas brasileiros: trigo, algodão, arroz, bovino, leite e milho. Eles analisam o período entre 1988 e 1996 e concluem que a criação de comércio superou amplamente o desvio. Estudos semelhantes de David e Nonnenberg (1997), Barcellos (2006) também analisam a evolução do comércio agrícola no Mercosul usando estatísticas descritivas. Por outro lado, Vasconcelos (2000) estima, sob a ótica de equilíbrio parcial, os impactos estáticos do processo de integração através da criação e desvio de comércio entre o Brasil e o Mercosul, para produtos industrializados selecionados. Por fim, Vasconcelos (2003) estuda o comércio entre Brasil e Mercosul sob a ótica do comércio intra-indústria, enquanto Mendes (1997) averigua os efeitos do Mercosul sobre o Brasil em termos locacionais (estaduais) e setoriais.

\subsection{Outros aspectos sobre acordos comerciais e Mercosul}

Diversos fenômenos relacionados ao Mercosul também foram pesquisados, além de comércio e bem estar, sobretudo empiricamente. A criação do bloco resultou em significante declínio nos preços dos produtos exportados para a região por não membros (CHANG; WINTERS, 2002). Além do mais, a queda nas tarifas brasileiras levaram as exportações argentinas para o Brasil a quadruplicarem entre 1992 e 1996, o que resultou em um maior investimento em tecnologia por parte das firmas argentinas (BUSTOS, 2011).

Como salientado anteriormente, o Mercosul tem muitos produtos cujas tarifas desviam da CET ou desviam internamente do livre comércio, o que o torna uma união aduaneira incompleta. Com base nisso, Olarreaga e Soloaga (1998) usam a literatura de tarifa endógena para mostrar que esses desvios de tarifas nos países membros do bloco podem ser explicados por lobby praticado pelas indústrias ou setores envolvidos. Por outro lado, Bohara, Gawande e Sanguinetti (2004) usam um modelo de tarifa endógena proposto por Richardson (1993) para chegar ao resultado de que o desvio de comércio a favor de parceiros menos eficientes provocado pela formação do bloco comercial irá diminuir 
endogenamente. Isso ocorre porque as indústrias que são protegidas por tarifas devido ao seu poder político terão esse poder diminuído com a integração comercial, o que resultaria em menor proteção a essas indústrias.

Diferentemente do resultado obtido por Bohara, Gawande e Sanguinetti (2004), Yeats (1998) mostra que a maioria dos produtos que tiveram um grande crescimento de comércio intra bloco foram aqueles em que os membros não tinham vantagem comparativa e não exportariam para o exterior. A causa disso estaria ligada às tarifas discriminatórias cobradas dos não membros, em média quatro a seis vezes mais altas que as cobradas em blocos como União Europeia e Nafta. No entanto, Nagarajan e General (1998) usam a mesma metodologia usada por Yeats (1998), com a diferença de que eles utilizam importações ao invés de exportações. O resultado obtido é de que não há evidência clara de desvio de comércio.

A regulação do setor automotivo no Mercosul mostra um setor altamente protegido historicamente, com Argentina e Brasil importando poucos carros até os anos 80. Entre 1996-1999, havia dois tipos de barreiras-não tarifárias (NTBs): uma cota nas importações bilaterais líquidas entre Brasil e Argentina, e uma restrição na balança comercial em nível global (BRAMBILLA, 2005). Além do mais, as importações desse setor estavam sujeitas a uma tarifa de $2 \%$ na Argentina no começo de 1995, e a uma tarifa de $32 \%$ no Brasil. No fim de 1999, os países do bloco adotaram uma tarifa externa comum de 35\%. Brambilla (2005) estima os impactos que o fim das NTBs e da adoção completa da união aduaneira teriam sobre o setor automotivo. Os efeitos do fim das NTBs dominam o nivelamento das tarifas, o que levaria a um aumento das importações do bloco e uma diminuição das exportações do Brasil para a Argentina.

Uma outra corrente da literatura estuda outros fatores que podem influenciar o comércio, além dos acordos comerciais. Porto et al. (2015) medem os impactos de medidas facilitadoras de comércio, como programa de operador econômico autorizado, janela única e arranjo de reconhecimento mútuo. O operador econômico autorizado é uma companhia envolvida em movimentação internacional de bens reconhecida pela aduana de um país por 
cumprir padrões e critérios exigidos por ela. A janela única é definida como um momento único de contato entre operadores de comércio externo e governo para o cumprimento de toda a burocracia referente ao comércio e à aduana. Já o arranjo de reconhecimento mútuo é um acordo internacional em que dois ou mais países reconhecem os padrões adotados por outros, inclusos medidas facilitadoras de comércio. Eles encontram que as duas primeiras aumentam o comércio. Souza e Burnquist (2011) constroem dois índices de simplificação de procedimentos de fronteira: um para exportação e outro para importação. Também encontram que melhorias nesses índices estimulam os fluxos de comércio entre os países. Por fim, Wilson, Mann e Otsuki (2005) usam outras quatro medidas: eficiência portuária, ambiente aduaneiro, ambiente regulatório e infraestrutura do setor de serviços. Eles também encontram efeitos positivos sobre o comércio, principalmente sobre as exportações. Há também estudos que analisam os efeitos da Organização Mundial do Comércio (OMC) sobre as transações. Reis et al. (2015) fornecem evidências de que a OMC teve um impacto profundo sobre o comércio de seus países membros, no período 1990-2009, especialmente sobre os países em desenvolvimento. Subramanian e Wei (2007) também estudam o mesmo fato em período diferente, e encontram um efeito maior da OMC sobre o comércio dos países desenvolvidos.

Os artigos que estudam blocos comerciais geralmente focam no aspecto econômico. No entanto, é preciso salientar que outros aspectos também importantes podem fundamentar a integração comercial. Por exemplo, questões políticas podem estar por trás desses acordos (MANZETTI, 1993), ou eles podem ser um primeiro passo rumo a um maior multilateralismo. ${ }^{10}$ Porém, estas questões não puramente comerciais estão fora do escopo desta dissertação.

10 Limão (2005) mostra que os acordos preferenciais comerciais (PTAs) norte americanos seriam "pedra no caminho" de uma liberalização multilateral. Por outro lado, Ethier et al. (1998) argumenta que o novo regionalismo ajudaria no processo de multilateralismo. 



\section{Metodologia}

O modelo de gravidade foi introduzido no estudo de comércio por Tinbergen et al. (1962), com o uso de uma equação análoga a da física para estudar as trocas comerciais entre países usando o PIB destes como "massa" e distância como variáveis explicativas. Apesar destes modelos terem uma regularidade empírica e explicarem bem o comércio internacional, eles foram deixados de lado pelos pesquisadores de comércio durante muitos anos, devido à falta de embasamento teórico. A equação de gravidade era vista mais como uma analogia física do que análise econômica (HEAD; MAYER, 2013).

Com o passar do tempo, alguns modelos teóricos que resultavam em equações de gravidade foram desenvolvidos, baseados principalmente em modelos de competição monopolística e do tipo Argminton. No entanto, foi na última década que surgiram novos modelos que permitiram uma grande evolução na integração entre teoria e parte empírica, com destaque para os trabalhos de Anderson e Wincoop (2001) e de Helpman, Melitz e Rubinstein (2007). O primeiro destaca a importância dos termos multilaterais de resistência na correção de viés de variável omitida. Estes termos controlam por custos de transação de um país em relação a todos os seus parceiros comerciais, muitas vezes não observáveis para o econometrista. Na prática, o jeito mais simples de implementação e teoricamente consistente é o uso de efeitos fixos. Já o segundo desenvolve um modelo de firmas heterogêneas de dois estágios, sendo que no primeiro se corrige o viés de seleção de firmas exportadoras, e no segundo estima-se uma equação de gravidade que permite a distinção entre margem intensiva e extensiva. ${ }^{1}$ No entanto, o principal problema com esta metodologia, comum a métodos baseados em Heckman, é a dificuldade de se achar uma restrição de exclusão (HEAD; MAYER, 2013).

A equação básica de gravidade na forma multiplicativa que especifica os termos multilaterais de resistência salientados por Anderson e Wincoop (2001) tem o seguinte formato:

1 Para uma resenha da literatura de gravidade, sua microfundamentação teórica e métodos de estimação, ver Head e Mayer (2013), Baldwin e Taglioni (2006), Bacchetta et al. (2012). 


$$
Y_{i j}=\alpha_{0} P i b_{i}^{\alpha_{1}} P i b_{j}^{\alpha_{2}} D_{i j}^{\alpha_{3}} e^{\theta_{i} d_{i}+\theta_{j} d_{j}} u_{i j}
$$

Esta equação mostra que o fluxo comercial uni-direcional entre dois países é proporcional ao produto dos PIBs deles e inversamente proporcional à distância entre eles. Como a teoria gravitacional explica o comércio bilateral uni-direcional, usaremos as importações como variável dependente. Não há nada de errado em usar o comércio total (soma de importações e exportações ou média delas), no entanto há o risco de viés de amostra pequena, já que se perde muitas observações (LIMãO, 2016). Também são inclusas as dummies $d_{i}$ e $d_{j}$ de importadores e exportadores, que controlam pela resistência multilateral. Tomando o logaritmo dos dois lados, temos a equação de gravidade na forma $\log$ linear:

$$
L n Y_{i j}=L n \alpha_{0}+\alpha_{1} L n P i b_{i}+\alpha_{2} L n P i b_{j}+\alpha_{3} L n D_{i j}+\theta_{i} d_{i}+\theta_{j} d_{j}+L n u_{i j}
$$

No entanto, há dois problemas com essa especificação. O primeiro é a eliminação de todos os zeros na variável dependente, uma situação recorrente em bases de dados de comércio, em que o comércio entre países é nulo. O outro tem a ver com consistência. Em modelos lineares estimados por OLS, a presença de heterocedasticidade afeta a eficiência das estimativas, no entanto, no modelo anterior em logaritmo teremos o problema de viés, como mostra Silva e Tenreyro (2006). Isso ocorre porque $E\left[L n U_{i j} \mid X\right]$ depende da média e de outros momentos de ordens maiores, como a variância. Portanto, quando a variância condicional do erro não for constante, ele será correlacionado com os regressores, exceto em condições muito específicas sobre a forma funcional do termo de erro.

Como forma de contornar os dois problemas anteriores, Silva e Tenreyro (2006) sugerem a utilização do estimador Poisson Pseudo-Maximum-Likelihood (PPML) para o modelo em nível. Para tanto, eles utilizam a equação em logaritmo mostrada anteriormente, exponenciam dos dois lados, e obtêm o seguinte modelo de gravidade: 


$$
Y_{i j}=\exp \left(L n \alpha_{0}+\alpha_{1} L n P i b_{i}+\alpha_{2} L n P i b_{j}+\alpha_{3} L n D_{i j}+\theta_{i} d_{i}+\theta_{j} d_{j}\right) u_{i j}
$$

ou, em notação reduzida:

$$
Y_{i j}=\exp \left(x_{i j} \beta\right) u_{i j}
$$

Neste modelo, utiliza-se a variável dependente em nível e as explicativas em logaritmo (com exceção das dummies). O estimador de PPML é obtido da função de probabilidade de uma Poisson, da qual se obtêm a função de log verossimilhança, e por fim, a seguinte condição de primeira ordem: ${ }^{2}$

$$
\sum_{i=1}^{n}\left[Y_{i j}-\exp \left(x_{i j} \hat{\beta}\right)\right] x_{i j}=0
$$

Para que esse estimador seja consistente, somente é necessário que a esperança condicional $E\left[Y_{i j} \mid x\right]=\exp \left(x_{i j} \beta\right)$ seja bem definida, ou seja, os dados não precisam seguir uma distribuição Poisson e nem a variável dependente precisa ser um número inteiro. Outra característica importante do PPML é que ele dá peso igual a todas observações, uma vantagem em termos de eficiência em relação a estimadores de Mínimos Quadrados Não-lineares, pois estes dão pesos maiores a observações em que $\exp \left(x_{i j} \beta\right)$ é grande. Porém, são estas observações com maior variância, em geral.

Nessa dissertação, o objetivo é medir os efeitos de criação, desvio de comércio e desvio de exportação decorrentes do Mercosul. Para tanto, o seguinte modelo (benchmark) será estimado usando diferentes estimadores e algumas variações do mesmo:

$$
Y_{i j, t}=P I B_{i, t}+P I B_{j, t}+X_{i j, t}+\operatorname{IntraPT} A_{i}+\operatorname{RestPT} A_{i}+\operatorname{ExpPT}_{i}+\eta_{t}+\mu_{i}+\mu_{j}+u_{i j, t}
$$

2 Arvis e Shepherd (2013) fazem uma derivação detalhada do estimador. 
A variavel dependente é a importação feita pelo país i do país j. As variáveis de PIB são auto explicativas, enquanto $X_{i j, t}$ são variáveis gravitacionais como população, distância, colônia, língua e adjacência e outros blocos comerciais como controle. A maioria dessas variáveis não varia no tempo, portanto são eliminadas quando usarmos um estimador de efeito fixo. $\eta_{t}$ são dummies de ano, enquanto $\mu_{i}$ e $\mu_{j}$ são efeitos fixos de importadores e exportadores, respectivamente. É importante ressaltar que há dois tipos de efeitos fixos: os de países (importadores e exportadores) e os de pares. Cada tipo será usado dependendo do estimador. Quando usamos os primeiros, é possível obter identificação das variáveis gravitacionais, enquanto que com os últimos não é possível obter das que não variam no tempo. Por fim, temos as três dummies de PTAs que irão identificar criação ou desvio de comércio e desvio de exportações, dentre as quais estão as dummies de Mercosul, nosso bloco de interesse. A dummy IntraPT $A_{i}$ capta criação de comércio e assume valor 1 se o comércio é realizado por dois países do bloco i, e 0 caso contrário. A dummy RestPT $A_{i}$ capta desvio de comércio e tem valor 1 se o importador pertence ao bloco e o exportador não, e 0 em outra situação, enquanto $\operatorname{Exp} P T A_{i}$ capta desvio de exportação e tem valor igual a 1 se o exportador é do bloco e o importador de fora. Portanto, teremos criação de comércio se os coeficientes das dummies IntraPT $A_{i}$ e RestPT $A_{i}$ forem positivos, porque os efeitos do acordo sobre as importações será de aumentá-las tanto internamente quanto de países de fora do bloco. Mas se IntraPT $A_{i}$ for positiva e RestPT $A_{i}$ negativa, teremos indícios de desvio de comércio, com o bloco tendo privilegiado importações de seus parceiros em detrimento dos países de fora. No entanto, é importante salientar que pode ter havido criação líquida de comércio neste último caso, pois a criação de comércio intra bloco pode ser maior que a diminuição do comércio com o resto do mundo. Por fim, se $\operatorname{ExpPT} A_{i}$ for negativo, o modelo indica desvio de exportações para dentro do bloco.

O modelo gravitacional que será usado pode ser estimado tanto usando o logaritmo das variáveis, o jeito mais comum na literatura, ou em nível. O primeiro caso sempre foi mais comum porque a equação original de gravidade é multiplicativa, o que trazia dificuldades às estimações devido à não linearidade da função. Além do mais, as bases de 
dados de comércio costumam ser muito grandes, portanto log linearizar a equação original era uma forma de facilitar as estimações. No entanto, com o avanço computacional e dos estimadores, como os de PPML, o uso do modelo em nível tem se popularizado cada vez mais.

Ao todo, serão reportadas cinco estimações do modelo apresentado, sendo que nas quatro primeiras as variáveis estão em logaritmo e na última a variável dependente está em nível, com o uso do estimador de Poisson. A primeira estimação será um OLS do modelo completo. A segunda será um estimador de efeito fixo, com o uso de efeitos fixos de pares ao invés de países. Vale notar que as variáveis invariantes no tempo são excluídas deste modelo. Para propósito de comparação, a terceira estimação será um estimador de efeitos aleatórios, usando efeitos fixos de países e as mesmas variáveis do OLS. O quarto estimador também será o de efeitos fixos. Neste caso, também usaremos "efeitos fixos" de exportadores/anos, que basicamente são interações entre dummies de exportadores e de anos e servem para controlar por características não observáveis dos exportadores que variam no tempo. Por fim, estimaremos um modelo em nível usando o PPML com efeitos fixos de pares.

A metodologia desenvolvida reporta um efeito médio sobre todo o período analisado, mas também seria interessante ver como a criação, o desvio de comércio e o desvio de exportações evoluem ao longo do tempo. Para tanto, dois modelos serão estimados por efeitos fixos com a interação entre dummies de ano e as de Mercosul a partir do ano de 1991. No primeiro, controla-se pelo PIB e população dos importadores e exportadores, por dummies de ano, por acordos comerciais e efeitos fixos de pares. No segundo, além dos efeitos fixos de pares, controla-se também por todas as características possíveis de exportadores não observáveis que variam no tempo através da interação entre dummies de exportadores e de anos. Nesse caso, só precisamos incluir no modelo as variáveis de importadores como PIB e população, além das duas dummies de criação e desvio dos blocos, porque há multicolinearidade com as outras variáveis. Para melhor visualização dos resultados, serão mostrados os gráficos com a evolução das variáveis de interesse, pois nos modelos estimados há um excesso de variáveis binárias. 
Outro exercício que será feito se refere à construção de um grupo contrafactual usando o primeiro modelo que analisa a dinâmica do Mercosul, discutido no parágrafo anterior. Com isso, é possível comparar o que teria ocorrido com o comércio caso o Mercosul não tivesse sido criado. Na prática, comparamos os valores previstos pelo modelo para o comércio com a existência do Mercosul com os valores previstos na ausência deste.

Por fim, feitas as avaliações do Mercosul em termos de criação e desvio de comércio, seria interessante avaliar se o bloco teve efeitos distintos sobre os setores econômicos. Para tanto, serão estimados os mesmos modelos que medem o efeito médio do acordo, mas para os setores de agricultura e indústria. Portanto, mesmo que as estimações anteriores mostrem que o bloco criou comércio, comportamento diferente pode ter ocorrido dentre os setores, notadamente a indústria. Além do mais, essa questão setorial é pouco estudada na literatura com o uso do instrumental tradicional de gravidade. Em geral, os artigos que analisaram essa questão usaram estatísticas descritivas, como índices de vantagem comparativa e de direcionamento das exportações, ou modelos de equilíbrio parcial, o que foi discutido na revisão de literatura.

\subsection{Base de dados}

O período escolhido para a base de dados compreende os anos de 1980 a 2014, sendo que a amostra de países inclue todos aqueles para os quais havia dados neste período, com exceção dos chamados micro estados, aqui definidos como países com uma população menor que 500 mil habitantes ou com uma área menor que $1000 \mathrm{~km}^{2}$. A lista dos 146 países utilizados se encontra na tabela 5, disponível no apêndice. Como o Mercosul foi criado em 1991, temos uma boa variação nos dados tanto antes quanto depois da criação. Os dados de importação foram obtidos da WITS (World Integrated Trade Solution) com a nomenclatura SITC (Standard International Trade Classification) Revisão 2, e estão em U\$1000. Esta mesma classificação foi usada para os dados de importações agrícolas e manufaturados. Os dados de PIB e população foram obtidos do Banco Mundial, com o PIB em dólares correntes. 
As variáveis de gravidade foram obtidas de uma base de dados da CEPII (Research and Expertise on the World Economy), que cobre o período de 1948 a 2006. São elas: contiguidade, língua, colônia e distância. Elas foram escolhidas por serem bastante utilizadas na literatura e pela importância delas para o comércio. Língua e colônia representam proximidade cultural/histórica, enquanto contiguidade denota a existência de fronteira entre países e distância é muito significativa para custos de transporte. Como essas variáveis não variam no tempo, elas foram replicadas até o ano de $2014 .^{3}$

Além das variáveis gravitacionais, foram inclusos alguns acordos comerciais como controles, e que não serão mostrados nos resultados para melhor visualização destes. São eles: Comunidade Andina (CAN), Asean Free Trade Area (AFTA), Asia Pacific Trade Agreement (APTA), Central American Common Market (CACM), North American Free Trade Agreement (NAFTA) e União Europeia (UE). Para cada um desses blocos foram inclusas as mesmas dummies mencionadas anteriormente para o Mercosul, ou seja, as que captam os efeitos de criação e desvio de comércio, e desvio de exportações.

3 Para maiores detalhes sobre a base, ver Head, Mayer e Ries (2010). 



\section{Resultados}

\subsection{Evolução do comércio}

Vamos começar a análise dos resultados mostrando quatro gráficos que retratam a evolução do comércio tanto entre os países do Mercosul quanto com o resto do mundo de 1980 até 2014. O objetivo é ver se, a partir desses gráficos, podemos ter uma noção ou intuição se o bloco contribuiu de alguma forma para o comércio da região. A figura 1 é sobre as importações. ${ }^{1}$ Elas foram normalizadas para 100 no ano de 1980, com o propósito de melhor visualização dos gráficos. A linha vermelha vertical marca o ano de 1991, no qual o Mercosul foi criado.

O gráfico mostra um crescimento tanto das importações intra bloco, quanto das importações que o bloco fez do resto do mundo. De 1991 até 2014, aquelas cresceram $344 \%$, enquanto estas cresceram $452 \%$. Mas se compararmos o crescimento visto durante os anos 90, até o ano de 1998 (antes da desvalorização do real e da crise argentina), as importações intra-bloco cresceram mais, cerca de $273 \%$, contra $153 \%$ das importações do

1 Os valores foram deflacionados com o uso do Wholesale Price Index $(2010=100)$ dos Estados Unidos, obtido da base de dados do Banco Mundial. Esse índice de preços se refere a um mix de produtos agrícolas e industriais em vários estágios de produção e distribuição, incluindo taxas de importação.

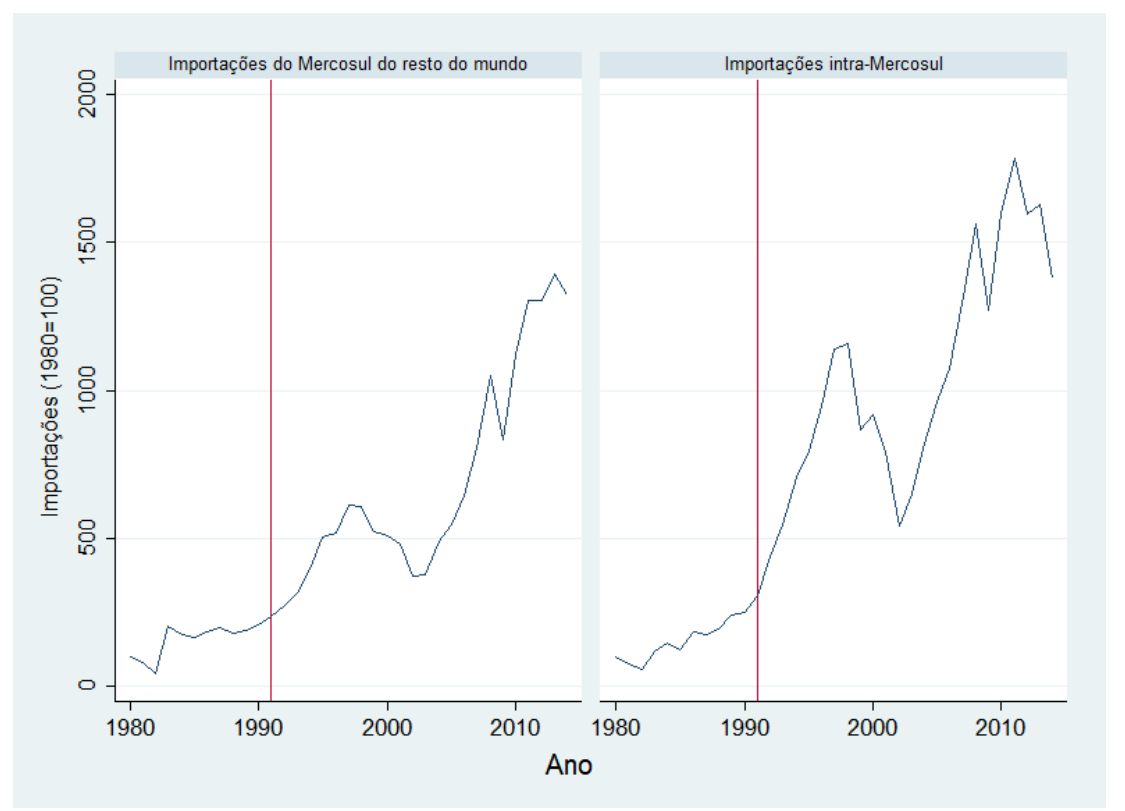

Figura 1 - Importações do Mercosul 


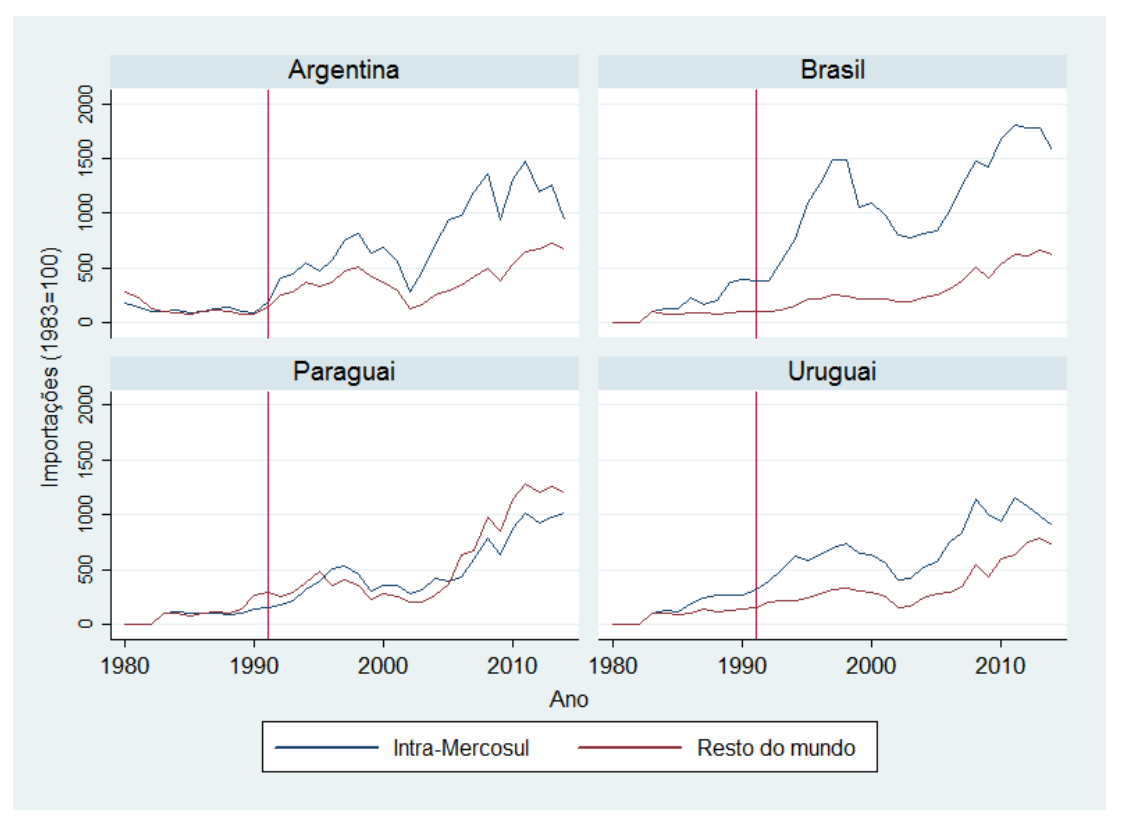

Figura 2 - Importações por países

resto do mundo. Portanto, esse gráfico mostra que os dois tipos de importações cresceram, mas que nos anos 90, pós criação do bloco, o comércio intra-bloco cresceu mais, o que pode ser um efeito do Mercosul. No entanto, ainda não temos evidências de criação ou desvio de comércio, pois outros fatores podem ter influído sobre as importações, como o crescimento mundial. A figura 2 desagrega as importações pelos países do bloco ${ }^{2}$ e mostra um distanciamento maior entre as importações para o Brasil, sugerindo que este foi o país que mais passou a importar de seus parceiros de bloco, mesmo quando as importações são normalizadas. Com relação aos outros países, nota-se um distanciamento semelhante entre Argentina e Uruguai, enquanto no Paraguai as importações do resto do mundo ultrapassam as intra-bloco no fim da década passada.

A figura 3 traz o comportamento das taxas de crescimento. De modo geral, as taxas das importações intra bloco e do resto mundo andam bem juntas, com exceção do pico que se vê no começo da década de 80. Entre o fim desta década e começo dos anos 90 temos um crescimento do comércio interno um pouco maior, possivelmente em consequência de efeitos antecipatórios da criação do bloco, e que se estende por alguns anos após o acontecimento, resultado encontrado por Freund e McLaren (1999), Magee (2008).

2 As importações foram normalizadas para $100 \mathrm{em} \mathrm{1983,} \mathrm{porque} \mathrm{não} \mathrm{há} \mathrm{dados} \mathrm{para} \mathrm{Brasil,} \mathrm{Paraguai} \mathrm{e}$ Uruguai entre 1980 e 1982. 


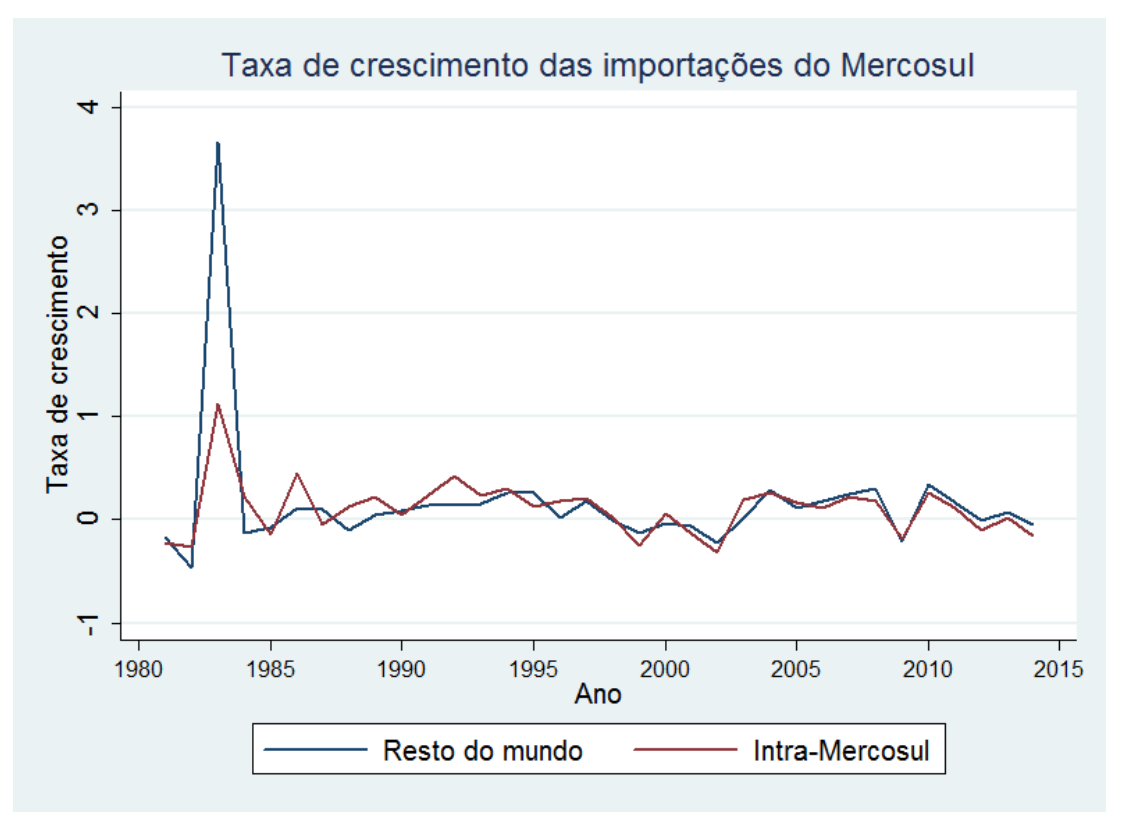

Figura 3

Por fim, a figura 4 traz o comportamento das exportações. Estas têm um comportamento semelhante ao das importações. O gráfico de exportações intra-Mercosul é igual ao de importações intra-Mercosul por construção. As exportações para os países que não são do bloco tiveram um crescimento modesto na década de 90, seguido de uma boa elevação na década passada, acompanhando o crescimento da economia mundial e a melhoria dos termos de troca, em especial das commodities, que ainda têm um peso considerável na balança comercial dos países da região. Assim como no caso das importações, houve uma pequena queda após a crise de 2008 e uma recuperação em seguida. A diferença é que, por fim, as exportações entraram em queda, e ainda não é possível saber quando terminará esse processo. Em suma, os dois tipos de exportações aumentaram, com destaque para as intra bloco. No entanto, como outros fatores tiveram influência no período, somente a análise econométrica permitirá analisar se há evidências de desvio de exportações.

\subsection{Efeitos do Mercosul}

A tabela 1 mostra os resultados da estimação de cinco modelos gravitacionais com o propósito de se avaliar se houve criação ou desvio de comércio e desvio de exportações 


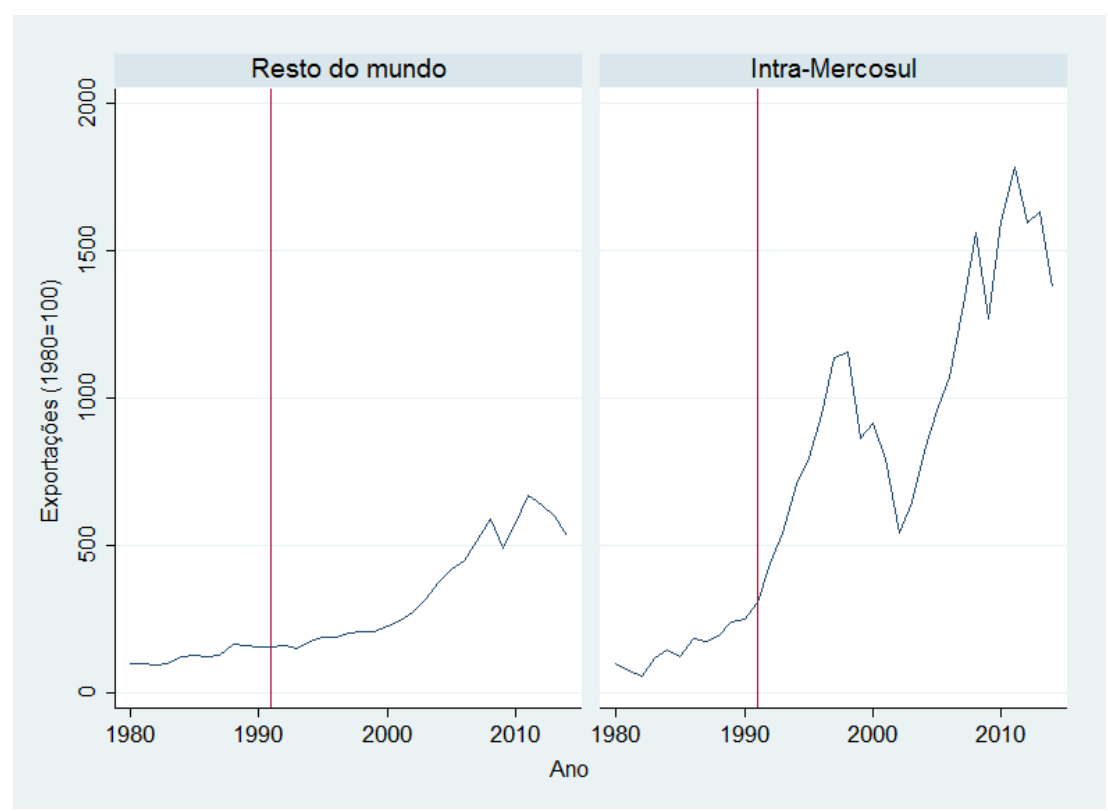

Figura 4 - Exportações do Mercosul

com o advento do Mercosul. ${ }^{3}$ Um fato que chama atenção é o grande crescimento no número de observações quando se utiliza o estimador de Poisson, o que é esperado, pois ele usa todos os zeros que são eliminados com a equação de gravidade no forma log linear.

Com relação às elasticidades das variáveis gravitacionais, os valores encontrados são semelhantes aos reportados na literatura internacional. Head e Mayer (2013) calculam estatísticas descritivas para as variáveis típicas de gravidade encontradas em todos os artigos publicados nos top 5 journals, no Journal of International Economics e na Review of Economics and Statistics entre 2006 e 2012. Eles calculam estatísticas para dois grupos, um com todos os tipos de estimações de gravidade, e o outro para as estimações estruturais, definida por eles como os artigos que usam efeitos fixos de países ou estimações ratio type. Portanto, os valores reportados aqui serão comparados às estatísticas estruturais do trabalho citado, já que em todas as nossas estimações foram utilizados algum tipo de efeito fixo.

As elasticidades do PIB de importadores encontradas estão entre 0.73 e 0.87 ,

3 A definição das variáveis contidas na tabela é a seguinte: Log exp PIB é o logaritmo do PIB do exportador, enquanto Log imp PIB se refere ao importador. Log imp pop é o logaritmo da população do importador, enquanto Log exp pop é o análogo do exportador. Intra Mercosul, Imp_Mercosul_rest e Exp_Mercosul_rest são, respectivamente, as dummies de criação e desvio de comércio e desvio de exportação. 


\begin{tabular}{|c|c|c|c|c|c|}
\hline Variáveis & $\begin{array}{c}\text { (1) } \\
\text { OLS } \\
\text { Log de imports }\end{array}$ & $\begin{array}{c}(2) \\
\text { Efeitos fixos } \\
\text { Log de imports }\end{array}$ & $\begin{array}{c}(3) \\
\text { Efeitos aleatórios } \\
\text { Log de imports }\end{array}$ & $\begin{array}{c}\text { (4) } \\
\text { Efeitos fixos } \\
\text { Log de imports }\end{array}$ & $\begin{array}{c}(5) \\
\text { Poisson } \\
\text { Imports }\end{array}$ \\
\hline Log exp PIB & $\begin{array}{c}0.501^{* * *} * \\
(0.0144)\end{array}$ & $\begin{array}{c}0.526 * * * \\
(0.0220)\end{array}$ & $\begin{array}{c}0.520^{* * *} \\
(0.0218)\end{array}$ & & $\begin{array}{c}0.608^{* * *} \\
(0.0342)\end{array}$ \\
\hline Log imp PIB & $\begin{array}{c}0.747^{* * * *} \\
(0.0151)\end{array}$ & $\begin{array}{c}0.873^{* * *} \\
(0.0208)\end{array}$ & $\begin{array}{c}0.860^{* * *} \\
(0.0208)\end{array}$ & $\begin{array}{c}0.856^{* * *} \\
(0.0110)\end{array}$ & $\begin{array}{c}0.739^{* * *} \\
(0.0342)\end{array}$ \\
\hline Log imp pop & $\begin{array}{c}0.578^{* * *} * \\
(0.0385)\end{array}$ & $\begin{array}{c}0.772^{* * *} \\
(0.0672)\end{array}$ & $\begin{array}{c}0.753^{* * *} \\
(0.0670)\end{array}$ & $\begin{array}{l}0.725^{* * *} \\
(0.0294)\end{array}$ & $\begin{array}{r}-0.0717 \\
(0.101)\end{array}$ \\
\hline Log exp pop & $\begin{array}{c}-0.675^{* * *} \\
(0.0393)\end{array}$ & $\begin{array}{c}-0.320^{* * *} \\
(0.0763)\end{array}$ & $\begin{array}{c}-0.350^{* * *} \\
(0.0762)\end{array}$ & & $\begin{array}{l}0.0617 \\
(0.103)\end{array}$ \\
\hline Contiguidade & $\begin{array}{c}0.665^{* * *} \\
(0.0246)\end{array}$ & & $\begin{array}{c}0.872^{* * * *} \\
(0.111)\end{array}$ & & \\
\hline Língua & $\begin{array}{c}0.872^{* * * *} \\
(0.0123)\end{array}$ & & $\begin{array}{l}1.046^{* * *} \\
(0.0430)\end{array}$ & & \\
\hline Colônia & $\begin{array}{c}0.760^{* * * *} \\
(0.0209)\end{array}$ & & $\begin{array}{c}0.874^{* * *} \\
(0.103)\end{array}$ & & \\
\hline Log de distância & $\begin{array}{c}-1.532 * * * \\
(0.00626)\end{array}$ & & $\begin{array}{c}-1.575^{* * *} \\
(0.0230)\end{array}$ & & \\
\hline Intra Mercosul & $\begin{array}{c}0.615^{* * *} \\
(0.0851)\end{array}$ & $\begin{array}{c}0.398^{* * * *} \\
(0.134)\end{array}$ & $\begin{array}{c}0.436^{* * * *} \\
(0.128)\end{array}$ & $\begin{array}{c}0.318^{* * *} \\
(0.0697)\end{array}$ & $\begin{array}{c}0.723^{* * *} \\
(0.129)\end{array}$ \\
\hline Imp_Mercosul_rest & $\begin{array}{l}0.127^{* *} \\
(0.0539)\end{array}$ & $\begin{array}{c}0.357^{* * *} \\
(0.0999)\end{array}$ & $\begin{array}{c}0.345^{* * * *} \\
(0.0992)\end{array}$ & $\begin{array}{c}0.309^{* * * *} \\
(0.0420)\end{array}$ & $\begin{array}{c}0.350^{\text {*** }} \\
(0.117)\end{array}$ \\
\hline Exp_Mercosul_rest & $\begin{array}{c}0.165^{* * *} \\
(0.0389)\end{array}$ & $\begin{array}{l}0.160^{* *} \\
(0.0764)\end{array}$ & $\begin{array}{l}0.160^{* *} \\
(0.0757)\end{array}$ & & $\begin{array}{c}-0.144^{*} \\
(0.0822)\end{array}$ \\
\hline Constante & $\begin{array}{c}-8.639^{* * *} \\
(0.989)\end{array}$ & $\begin{array}{c}-33.38^{* * *} \\
(1.747)\end{array}$ & $\begin{array}{c}-19.75^{* * *} \\
(1.735)\end{array}$ & & \\
\hline Observações & 364,055 & 364,055 & 364,055 & 375,893 & 578,187 \\
\hline $\mathrm{R}-2$ & 0.741 & 0.321 & 0.737 & 0.878 & \\
\hline Dummies de anos & Sim & Sim & Sim & Não & Sim \\
\hline EF Exp e Imp & Sim & Não & Sim & Não & Não \\
\hline EF de pares & Não & Sim & Não & Sim & Sim \\
\hline EF exp-ano & Não & Não & Não & Sim & Não \\
\hline Número de pares & & 19,306 & 19,306 & 18,825 & 19,305 \\
\hline
\end{tabular}

Tabela 1 - Modelos estáticos

sendo que na literatura internacional a média é 0.74 e a mediana é 0.86 para os artigos estruturais. Para as elasticidades do PIB dos exportadores, os valores são bem regulares para os modelos log linearizados, estando entre 0.50 e 0.52 , enquanto no modelo em nível esse valor é 0.60 . Na literatura a média é 0.58 e a mediana é 0.67 . As outras variáveis gravitacionais são significativas e também possuem o sinal esperado pela teoria. Para contiguidade, são encontrados valores de 0.66 e 0.87 , com média de 0.66 e mediana 0.52 . Com relação à distância, foram estimados valores de -1.53 e -1.57 (média de -1.1 e mediana -1.14). Por fim, temos colônia e língua, duas variáveis tidas como proxies para proximidade cultural/histórica. Para a primeira, encontramos estimativas de 0.76 e 0.87 (média de 0.75 e mediana de 0.84 ), e para a última os valores são 0.87 e 1.04 (média de 0.39 e mediana de 0.33). Neste último caso, a diferença observada pode ser fruto do tipo de variável utilizada. No nosso caso, utilizamos uma dummy que assume valor 1 se dois países falam a mesma língua, no entanto há artigos que incluem dummmies para várias línguas, como inglês e 
espanhol por exemplo. ${ }^{4}$

Para a dummy de Mercosul relacionada à criação de comércio (Intra-Mercosul) encontramos valores que vão de 0.31 a 0.61 para os modelos na forma log linear. Isso indica uma criação de comércio entre os países do bloco que vão de $37 \%\left(e^{0.318}-1\right)$ a $84 \%$. Para o modelo em nível estimado por Poisson, o coeficiente indica um aumento de comércio intra-bloco de 106\%. Magee (2008) encontra um valor de 0.441 (55\%) para a mesma dummy usando um modelo com efeito fixo de pares e dummies de ano semelhante ao modelo 2, no qual encontramos um valor de 0.398 significativo a $1 \%$. Este mesmo artigo também encontra um forte efeito de 1.657 (424\%) em uma estimação com efeitos fixos de exportadores/anos e importadores/anos. Com relação à dummy de desvio de comércio, as estimativas encontradas se situam entre 0.127 e 0.357 , indicando um crescimento das importações de fora de $13 \%$ a $42 \%$. Magee (2008) encontra um valor não significativo para o Mercosul (0.022) na estimação comparável ao modelo 2. De modo geral, as nossas estimações sugerem um efeito maior do bloco sobre o comércio interno, em comparação ao realizado com o resto do mundo.

Os efeitos encontrados na literatura internacional para o impacto de acordos regionais de comércio (RTA) são semelhantes ao que encontramos em nossas estimações. Cipollina e Salvatici (2010) também calculam estatísticas descritivas para os efeitos sobre o comércio de RTAs com base em 1867 estimativas e acham um efeito médio de 0.59, enquanto Head e Mayer (2013) acham uma média de 0.36 para os modelos estruturais. A média das nossas estimativas é 0.67 , obtida com os valores das dummies de criação de comércio para os modelos na forma log linear, pois os estudos anteriores não indicam se incluíram estimações com PPML nas estatísticas. Estes dois artigos também reportam estatísticas para os dois maiores blocos econômicos: União Europeia e Nafta. Head e Mayer (2013) acham médias de 0.16 e 0.76, respectivamente, enquanto Cipollina e Salvatici (2010) encontram 0.52 e 0.90 . As nossas estimativas têm média de 0.12 e 0.42 , mais parecidas com os valores estruturais dos primeiros.

De modo geral, os modelos estimados mostram evidências de que o Mercosul

$\overline{4}$ Ver Azevedo (2004) para um exemplo deste último caso. 
resultou em criação de comércio, ao invés de desvio, porque todas as dummies de criação e desvio de comércio são positivas e significantes. Portanto, o efeito do Mercosul sobre o comércio foi de aumento com todos os tipos de parceiros para os países do Mercosul. Com relação à variável de desvio de exportação, ela é positiva e significante nos três primeiros modelos e negativa e significante a $10 \%$ no último modelo, o que indica que não houve evidências de desvio de exportação em direção aos parceiros de bloco na maioria das estimações. Ela não aparece no modelo 4 por causa de multicolinearidade com os efeitos fixos de exportadores/anos.

\subsection{Dinâmica do Mercosul}

Na seção anterior foram reportados os resultados de alguns modelos com o objetivo de ver se houve criação ou desvio de comércio e desvio de exportações com o surgimento do Mercosul. No entanto, uma pergunta natural que surge é se não houve efeitos distintos ao longo do tempo. Por exemplo, a criação de comércio poderia ser maior logo após o surgimento do bloco, e ir diminuindo alguns anos depois. Para avaliarmos essa possibilidade, serão estimados dois modelos quase iguais aos modelos 2 e 4 da seção anterior, com a diferença que agora incluiremos interações entre as variáveis de Mercosul e dummies de ano. Isso permitirá analisar os efeitos do Mercosul através dos anos, ao contrário da seção anterior, na qual obtivemos um efeito médio sobre todo o período.

Os dois modelos utilizam as variáveis em logaritmo. No primeiro, controla-se pelos PIBs e populações dos importadores e exportadores, pelos outros blocos comerciais, além de se utilizar dummies de anos e efeitos fixos de pares. Já no segundo modelo usamos efeitos fixos de pares e de exportadores/ano. Com isso, não é necessário incluir o PIB e população dos exportadores e dummies de anos. Além do mais, neste último modelo não é possível verificar desvio de exportações por conta de multicolinearidade com os efeitos fixos de exportadores/ano.

O modelo em nível e o estimador de Poisson, que permite o uso de mais informação, não foram utilizados pelas dificuldades computacionais relacionadas à convergência das 


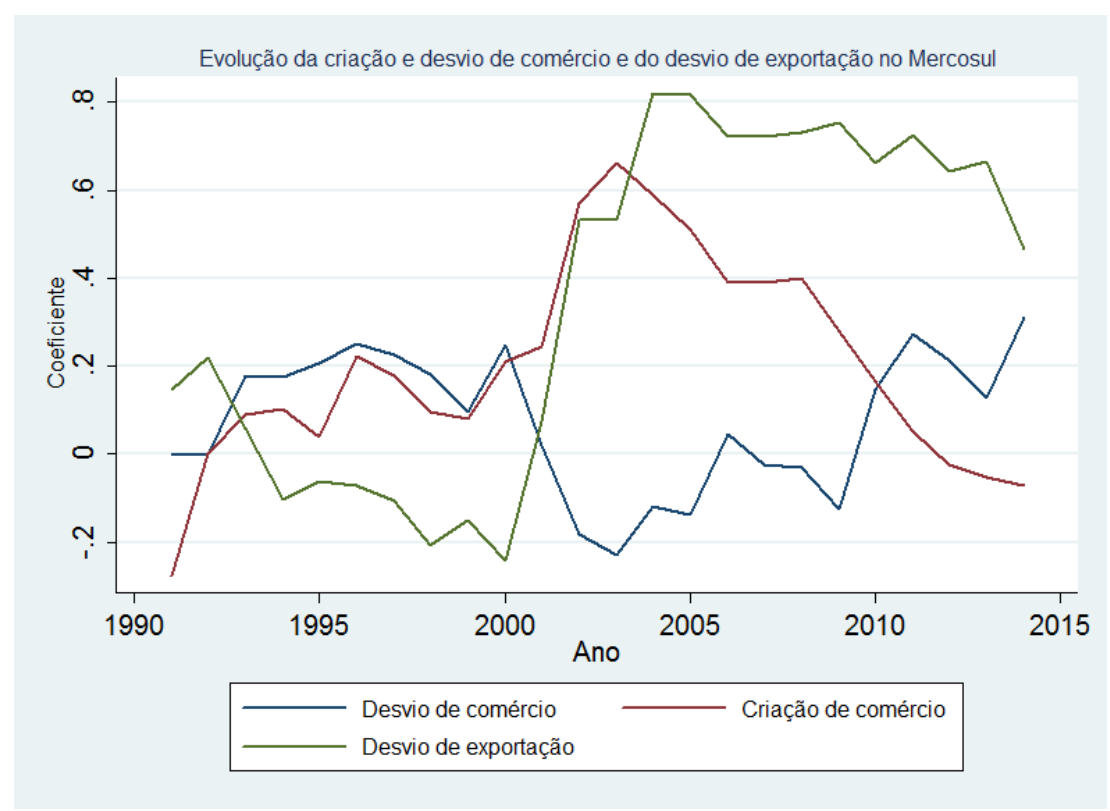

Figura 5

estimativas quando se tem muitas variáveis binárias. Posto isso, a seguir serão mostrados os gráficos com a evolução das nossas variáveis de interesse. A tabela 4 com os resultados está no apêndice.

Os gráficos mostram a evolução dos coeficientes ao longo dos anos das dummies de interesse relacionadas ao Mercosul citadas anteriormente, a ver, criação e desvio de comércio, e desvio de exportação. Dito isso, definimos que a assinatura de um acordo comercial resultou em criação de comércio quando as duas primeiras dummies são positivas, ou seja, o bloco exerceu um efeito positivo tanto sobre o comércio com os parceiros de bloco quanto com os de fora. Por outro lado, quando a dummy de criação de comércio é positiva mas a de desvio é negativa, dizemos que houve desvio de comércio, pois privilegiou-se o comércio intra-bloco em detrimento dos demais. No entanto, é possível que haja criação líquida de comércio neste último caso, se a criação de comércio intra-bloco for maior que a redução nas transações com os demais países.

A figura 5 mostra os resultados do primeiro modelo estimado, descrito anteriormente. Ela nos mostra que houve uma pequena criação de comércio na década de 90, enquanto na década passada houve um pequeno desvio e um razoável efeito sobre as importações intra-bloco, sendo este maior que o desvio verificado, indicando criação líquida. Importante 


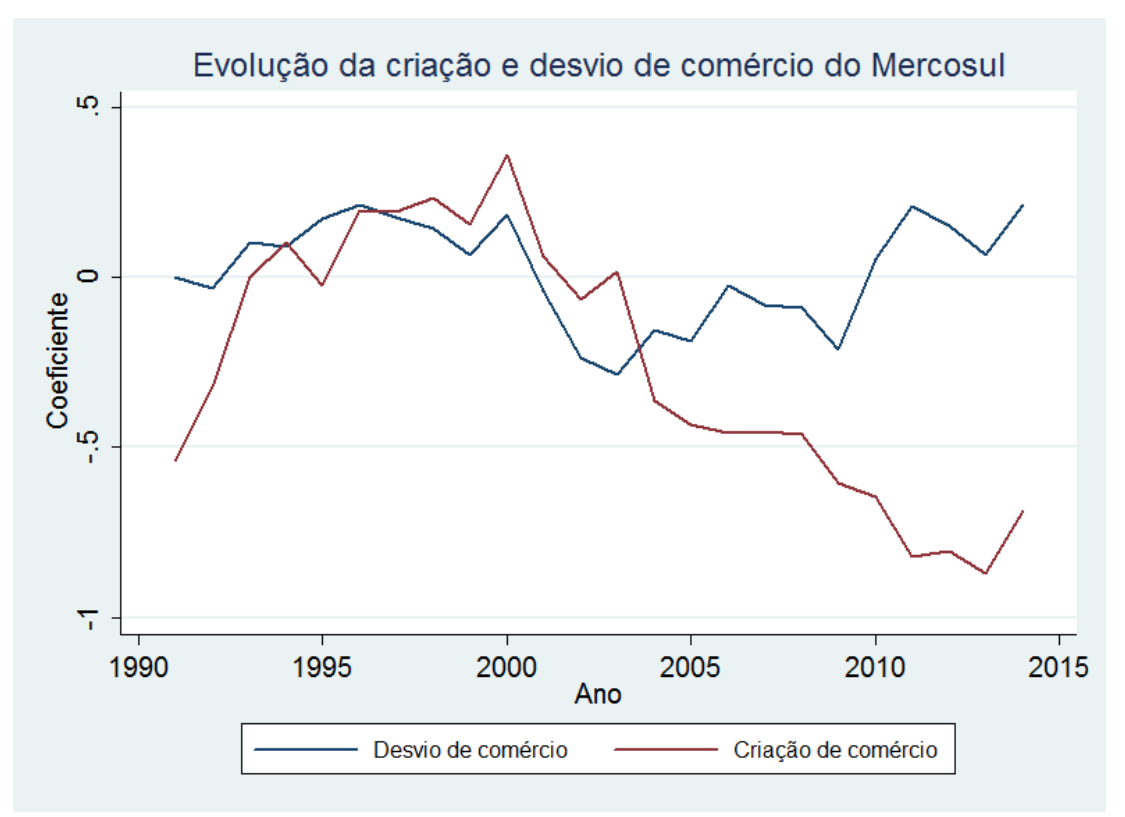

Figura 6

notar que o efeito do Mercosul sobre o comércio intra-bloco vem caindo sistematicamente desde meados da última década, provavelmente em função do surgimento de novas barreiras comerciais, com destaque para as medidas protecionistas adotadas pela Argentina. Com relação ao efeito sobre as exportações dos países do Mercosul para o exterior, ele diminue na década de 90, o que seria evidência de desvio de exportações para os parceiros de bloco. Já na década passada, houve um aumento desse efeito sobre as exportações, auxiliado pela melhoria dos termos de troca e do crescimento da economia mundial vivenciados durante esse período. Por fim, temos a figura 6, referente ao segundo modelo estimado, que analisa a criação e desvio de comércio controlando por todos os tipos de efeitos fixos (pares e exportadores/ano) sem que uma das dummies de criação e desvio de comércio seja omitida por multicolinearidade, mas que não permite a inclusão da dummy de desvio de exportação.

Esse último gráfico apresenta um comportamento um pouco diferente do primeiro. Ele também mostra uma pequena criação de comércio na década de 90, no entanto, as dummies de criação e desvio caem na década passada, com destaque para a primeira, que possui valores negativos praticamente a década toda, indicando um possível retrocesso na política comercial do bloco. Apesar disso, a maioria dos coeficientes encontrados é não significativa. Este resultado pode parecer contraditório aos efeitos encontrados na seção 
anterior, no entanto, é importante notar que antes foram calculados efeitos médios sobre todo o período considerado, enquanto aqui os efeitos são anuais a partir de 1991. Portanto, esse último modelo evidencia um impacto positivo do Mercosul sobre o comércio logo no período de dez anos pós assinatura do Tratado de Assunção, além de ter a vantagem de controlar por efeitos não observáveis de exportadores que variam no tempo, o que não foi feito no modelo anterior. A única desvantagem é a impossibilidade de avaliar a evolução do desvio de exportações quando se inclui esse tipo de efeito fixo.

\subsection{Contrafactual}

Uma questão importante a ser abordada seria estabelecer um contrafactual para o comércio do Mercosul, ou seja, o que teria ocorrido caso o acordo não tivesse sido estabelecido. Para tanto, será usado o primeiro modelo que verificou a dinâmica do Mercosul, com efeitos fixos de pares. A construção do contrafactual é simples, basta usarmos este modelo assumindo que as dummies de Mercosul tenham valor igual a zero a partir de 1991. Com isso, temos a previsão de qual teria sido o comércio sem o acordo e podemos fazer uma comparação com os valores previstos na presença do mesmo. A figura 7 mostra a evolução da previsão das importações que o Mercosul realizou do resto do mundo de acordo com este modelo.

Este gráfico mostra que o Mercosul teve um efeito maior na década de 90, comparado ao contrafactual. Apesar da diferença parecer bem pequena, é preciso relembrar que as importações estão em logaritmo, portanto a diferença é maior em nível. Como o modelo estimado aqui é o mesmo que o primeiro modelo que verificou a dinâmica do acordo, pelo mesmo motivo aqui também não foi estimado um modelo com as importações em nível, por Poisson. O excesso de dummies dificulta bastante a convergência das estimativas. Outro ponto interessante é que na primeira metade da década passada e no fim dela as importações teriam sido maiores sem a presença do bloco, o que pode indicar um possível recrudescimento da política comercial dele ou de seus membros na década passada. A figura 8 reporta um grupo contrafactual somente para as importações intra-bloco. 


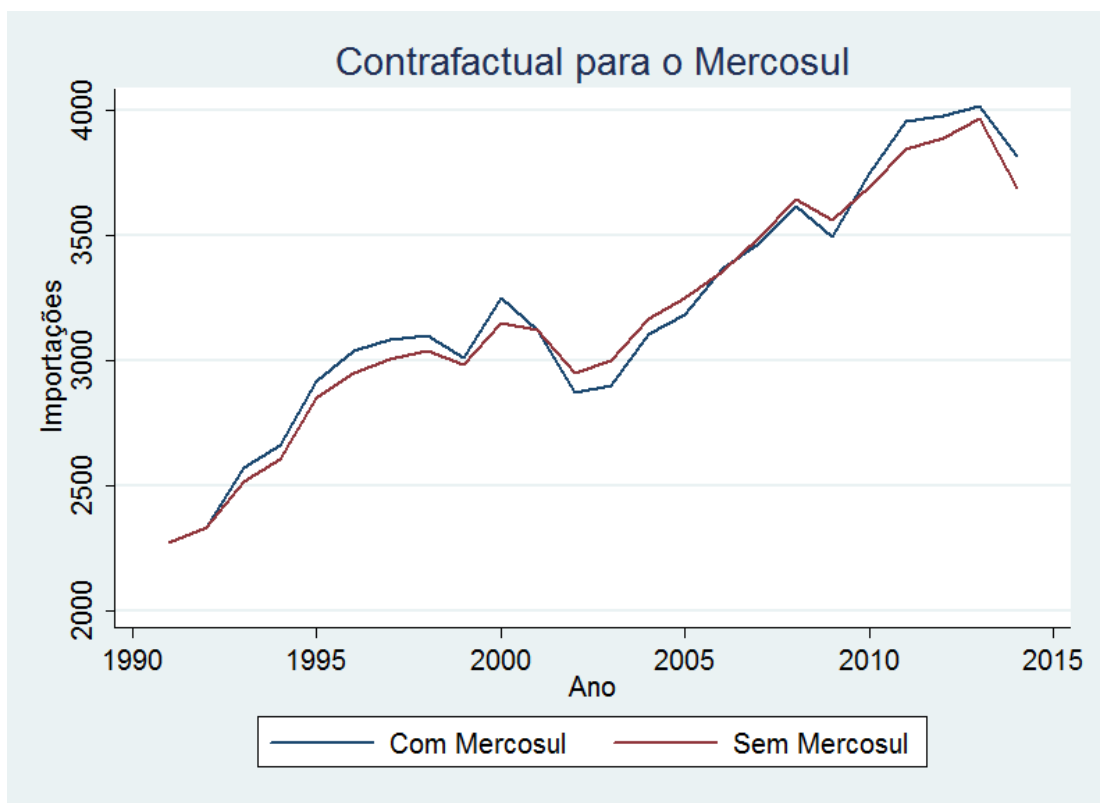

Figura 7 - Importações do resto do mundo

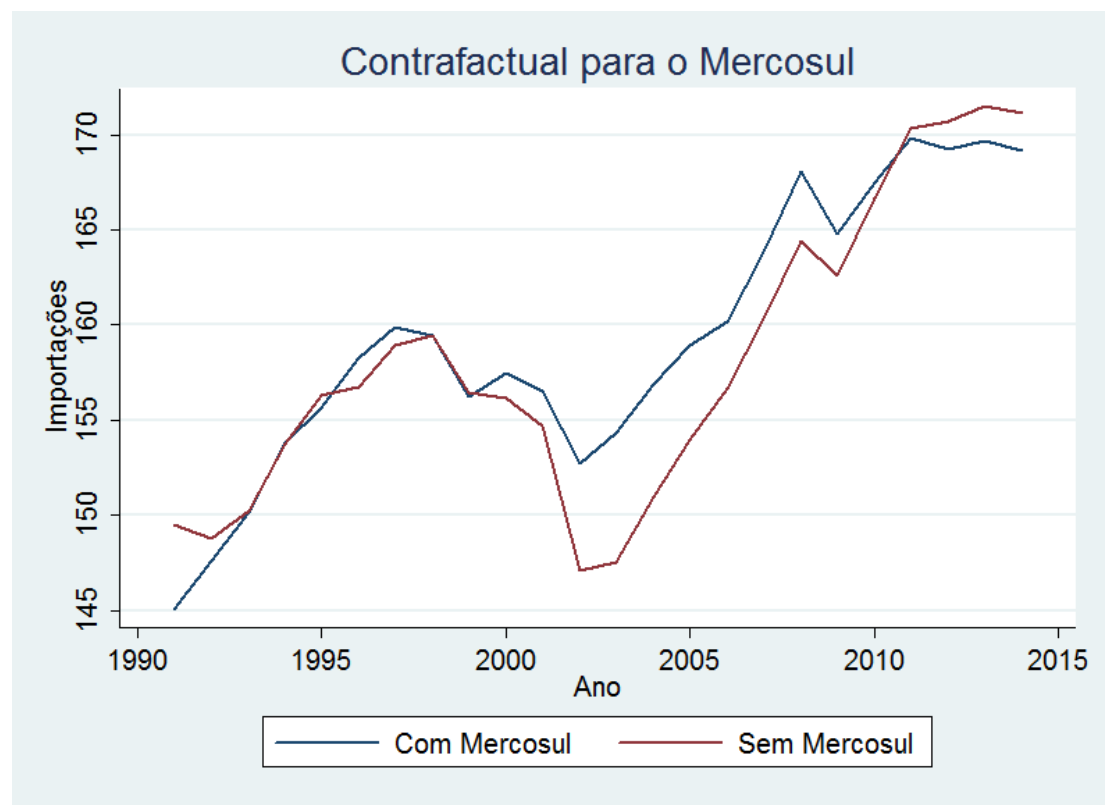

Figura 8 - Importações intra-Mercosul 


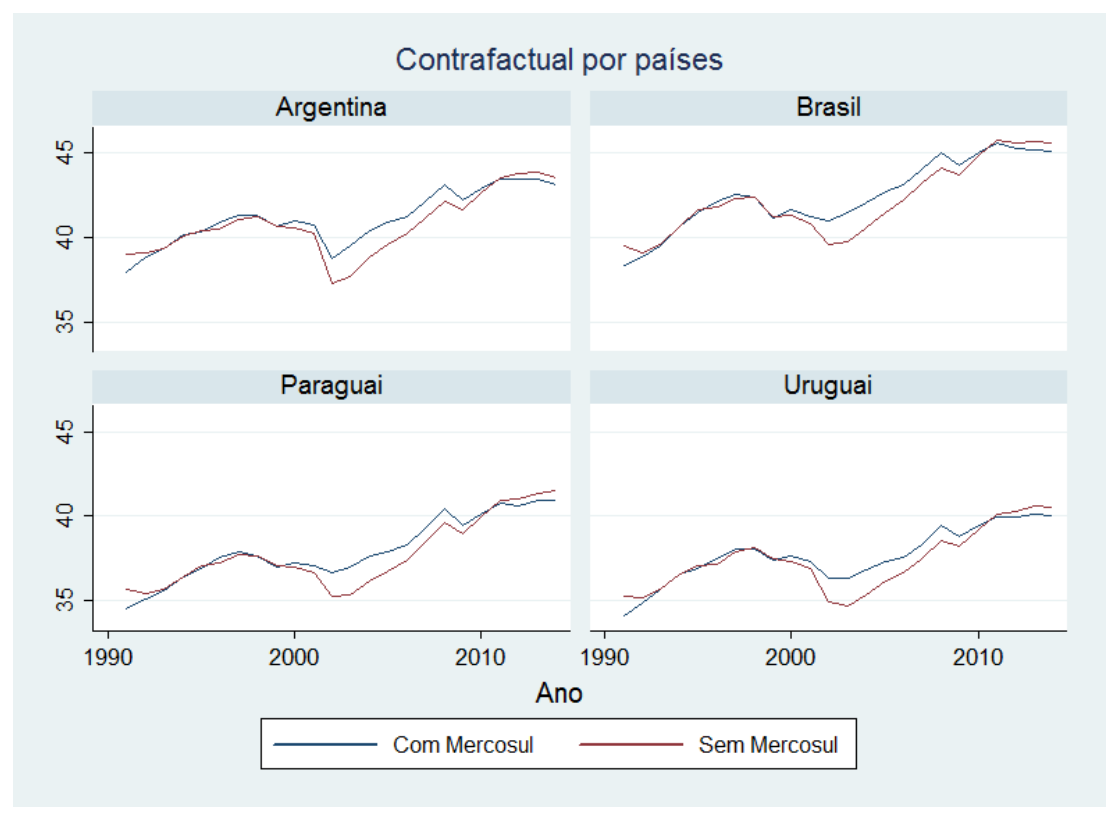

Figura 9 - Importações intra-Mercosul

Diferentemente do gráfico anterior, agora o Mercosul teve um efeito maior sobre as importações intra-bloco na década passada, sendo que na década de 90 estas importações seriam parecidas sob os dois cenários. Estes dois gráficos podem indicar uma maior preferência por produtos do bloco na década passada, em detrimento dos produtos de fora, ou que o bloco tenha ajudado a manter o comércio interno no período pós desvalorização do real e de grave crise argentina. Por fim, a figura 9 mostra as importações intra-bloco desagregadas por países e seus respectivos contrafactuais. Se antes as previsões foram agregadas para todos os países do acordo, aqui simplesmente usamos o modelo estimado para fazer as previsões individuais por países.

Este último gráfico tem um comportamento muito similar ao anterior, pois também exibe um efeito maior do Mercosul sobre as importações que os países fizeram dos parceiros de bloco na década passada, em comparação ao grupo contrafactual. Como as diferenças nas importações com e sem Mercosul são similares para os quatro países, esse gráfico sugere que a ausência do bloco teria um efeito proporcionalmente maior sobre as importações dos países com economias menores, o Paraguai e o Uruguai. Essa evidência pode ser fruto de um ganho de mercado por firmas dos países maiores, Brasil e Argentina, que aproveitaram o acordo e aumentaram suas exportações para os países menores. Em suma, esses gráficos sugerem que a existência do Mercosul foi mais importante para as importações de fora do 


\begin{tabular}{|c|c|c|c|c|c|}
\hline Variáveis & $\begin{array}{c}\text { (1) } \\
\text { OLS } \\
\text { Log de AgrImports }\end{array}$ & $\begin{array}{c}(2) \\
\text { Efeitos fixos } \\
\text { Log de AgrImports }\end{array}$ & $\begin{array}{c}(3) \\
\text { Efeitos aleatórios } \\
\text { Log de AgrImports }\end{array}$ & $\begin{array}{c}\text { (4) } \\
\text { Efeitos fixos } \\
\text { Log de AgrImports }\end{array}$ & $\begin{array}{c}5) \\
\text { Poisson } \\
\text { AgrImports } \\
\end{array}$ \\
\hline Log exp PIB & $\begin{array}{c}0.226^{* * * *} \\
(0.0152)\end{array}$ & $\begin{array}{c}0.256^{* * *} \\
(0.0239)\end{array}$ & $\begin{array}{c}0.249^{* * *} * \\
(0.0237)\end{array}$ & & $\begin{array}{c}0.207^{* * * *} \\
(0.0301)\end{array}$ \\
\hline Log imp PIB & $\begin{array}{c}0.645^{* * *} \\
(0.0169)\end{array}$ & $\begin{array}{c}0.798^{* * *} * \\
(0.0237)\end{array}$ & $\begin{array}{c}0.783^{* * *} \\
(0.0235)\end{array}$ & $\begin{array}{c}0.778^{* * *} \\
(0.0123)\end{array}$ & $\begin{array}{c}0.715^{* * *} \\
(0.0354)\end{array}$ \\
\hline Log imp pop & $\begin{array}{c}0.665^{* * *} \\
(0.0417)\end{array}$ & $\begin{array}{c}0.784^{* * *} \\
(0.0721)\end{array}$ & $\begin{array}{c}0.771^{* * *} \\
(0.0716)\end{array}$ & $\begin{array}{c}0.696^{* * * *} \\
(0.0310)\end{array}$ & $\begin{array}{c}0.473^{* * *} \\
(0.103)\end{array}$ \\
\hline Log exp pop & $\begin{array}{c}-0.437^{* * *} \\
(0.0453)\end{array}$ & $\begin{array}{c}-0.336^{* * *} \\
(0.0908)\end{array}$ & $\begin{array}{c}-0.361^{* * *} \\
(0.0905)\end{array}$ & & $\begin{array}{c}-0.496^{* * * *} \\
(0.138)\end{array}$ \\
\hline Contiguidade & $\begin{array}{c}0.822^{* * *} \\
(0.0250)\end{array}$ & & $\begin{array}{c}1.079^{* * *} \\
(0.101)\end{array}$ & & \\
\hline Língua & $\begin{array}{c}0.707^{* * *} * \\
(0.0140)\end{array}$ & & $\begin{array}{c}0.712^{* * *} \\
(0.0483)\end{array}$ & & \\
\hline Colônia & $\begin{array}{c}1.001^{* * *} \\
(0.0204)\end{array}$ & & $\begin{array}{l}1.168^{* * *} \\
(0.0974)\end{array}$ & & \\
\hline Log de distância & $\begin{array}{c}-1.344 * * * \\
(0.00688)\end{array}$ & & $\begin{array}{c}-1.376^{* * *} \\
(0.0239)\end{array}$ & & \\
\hline Intra Mercosul & $\begin{array}{c}1.168^{* * *} \\
(0.102)\end{array}$ & $\begin{array}{c}0.678^{* * *} \\
(0.236)\end{array}$ & $\begin{array}{c}0.728^{* * *} \\
(0.214)\end{array}$ & $\begin{array}{c}0.250^{* * * *} \\
(0.0929)\end{array}$ & $\begin{array}{c}0.478^{* * *} \\
(0.106)\end{array}$ \\
\hline Imp_Mercosul_rest & $\begin{array}{c}0.485^{* * *} \\
(0.0567)\end{array}$ & $\begin{array}{c}0.584^{* * *} \\
(0.104)\end{array}$ & $\begin{array}{c}0.577^{* * *} \\
(0.103)\end{array}$ & $\begin{array}{c}0.506^{* * *} \\
(0.0460)\end{array}$ & $\begin{array}{c}0.227^{* *} \\
(0.102)\end{array}$ \\
\hline Exp_Mercosul_rest & $\begin{array}{c}0.510^{* * * *} \\
(0.0435)\end{array}$ & $\begin{array}{c}0.573^{* * *} * \\
(0.0853)\end{array}$ & $\begin{array}{c}0.573^{* * *} \\
(0.0845)\end{array}$ & & $\begin{array}{l}0.185 \\
(0.113)\end{array}$ \\
\hline Constante & $\begin{array}{c}-7.323^{* * *} \\
(1.100)\end{array}$ & $\begin{array}{c}-26.07^{* * *} \\
(1.979)\end{array}$ & $\begin{array}{c}-13.90^{* * *} \\
(1.950)\end{array}$ & & \\
\hline Observações & 299,871 & 299,871 & 299,871 & 307,550 & 535,131 \\
\hline $\mathrm{R}-2$ & 0.648 & 0.164 & 0.642 & 0.843 & \\
\hline Dummies de anos & Sim & Sim & Sim & Não & Sim \\
\hline EF Exp e Imp & Sim & Não & Sim & Não & Não \\
\hline EF de pares & Não & Sim & Não & Sim & Sim \\
\hline EF exp-ano & Não & Não & Não & Sim & Não \\
\hline Número de pares & & 17,778 & 17,778 & 16,643 & 17,777 \\
\hline
\end{tabular}

Tabela 2 - Estimações para a agricultura

bloco na década de 90, enquanto as importações intra-bloco foram mais beneficiadas na década passada, o que poderia indicar uma mudança na política comercial e prioridades do bloco.

\subsection{Estimações setoriais}

O Mercosul já foi analisado neste trabalho através de modelos nos quais se obteve o efeito médio do bloco, e através de modelos em que foram verificados se o acordo teve efeitos diferentes ao longo do tempo. Nesta seção será estimado os efeitos do bloco sobre dois setores da economia: a agricultura e a indústria. Anteriormente, vimos que o Mercosul criou comércio como um todo, no entanto, pode ter havido efeitos distintos sobre estes dois setores. A tabela 2 traz as estimações dos mesmos modelos estimados anteriormente que avaliaram o efeito médio do acordo, com a diferença de que agora a variável dependente são as importações de produtos agrícolas, e não importações totais. 


\begin{tabular}{|c|c|c|c|c|c|}
\hline Variáveis & $\begin{array}{c}\text { OLS } \\
\text { OLg de ManufImports } \\
\end{array}$ & $\begin{array}{c}(2) \\
\text { Efeitos fixos } \\
\text { Log de ManufImports }\end{array}$ & $\begin{array}{c}(3) \\
\text { Efeitos aleatórios } \\
\text { Log de ManufImports }\end{array}$ & $\begin{array}{c}\text { (4) } \\
\text { Efeitos fixos } \\
\text { Log de Manuflmports } \\
\end{array}$ & $\begin{array}{c}(5) \\
\text { Poisson } \\
\text { ManufImports }\end{array}$ \\
\hline Log exp PIB & $\begin{array}{c}0.364^{* * *} \\
(0.0143)\end{array}$ & $\begin{array}{c}0.394^{* * *} \\
(0.0225)\end{array}$ & $\begin{array}{c}0.389^{* * *} * \\
(0.0223)\end{array}$ & & $\begin{array}{c}0.575^{* * *} \\
(0.0365)\end{array}$ \\
\hline Log imp PIB & $\begin{array}{c}0.821^{* * *} \\
(0.0151)\end{array}$ & $\begin{array}{c}0.946^{* * *} \\
(0.0216)\end{array}$ & $\begin{array}{c}0.931^{* * *} \\
(0.0216)\end{array}$ & $\begin{array}{c}0.898^{* * * *} \\
(0.0112)\end{array}$ & $\begin{array}{c}0.784^{* * *} \\
(0.0421)\end{array}$ \\
\hline Log imp pop & $\begin{array}{c}0.135^{* * *} \\
(0.0386)\end{array}$ & $\begin{array}{c}0.206^{* * *} * \\
(0.0713)\end{array}$ & $\begin{array}{c}0.193^{* * *} * \\
(0.0711)\end{array}$ & $\begin{array}{c}0.149^{* * * *} \\
(0.0296)\end{array}$ & $\begin{array}{c}-0.251^{*} \\
(0.133)\end{array}$ \\
\hline Log exp pop & $\begin{array}{c}0.199^{* * * *} \\
(0.0386)\end{array}$ & $\begin{array}{l}0.185^{* *} \\
(0.0821)\end{array}$ & $\begin{array}{l}0.171^{\text {** }} \\
(0.0818)\end{array}$ & & $\begin{array}{c}0.625^{* * *} * \\
(0.195)\end{array}$ \\
\hline Contiguidade & $\begin{array}{c}0.684^{* * * *} \\
(0.0249)\end{array}$ & & $\begin{array}{c}0.860^{\text {*** }} \\
(0.106)\end{array}$ & & \\
\hline Língua & $\begin{array}{c}0.973^{* * *} \\
(0.0124)\end{array}$ & & $\begin{array}{c}1.073^{* * *} \\
(0.0417)\end{array}$ & & \\
\hline Colônia & $\begin{array}{c}0.623^{* * *} * \\
(0.0211)\end{array}$ & & $\begin{array}{c}0.735^{* * *} \\
(0.0973)\end{array}$ & & \\
\hline Log de distância & $\begin{array}{c}-1.650^{* * *} \\
(0.00628)\end{array}$ & & $\begin{array}{c}-1.700^{* * *} \\
(0.0221)\end{array}$ & & \\
\hline Intra Mercosul & $\begin{array}{c}0.454^{* * *} \\
(0.0796)\end{array}$ & $\begin{array}{c}0.471^{* *} \\
(0.216)\end{array}$ & $\begin{array}{c}0.538^{* * *} \\
(0.204)\end{array}$ & $\begin{array}{c}0.898^{* * * *} \\
(0.0904)\end{array}$ & $\begin{array}{c}0.837^{* * *} \\
(0.181)\end{array}$ \\
\hline Imp_Mercosul_rest & $\begin{array}{c}0.206^{\text {*** }} \\
(0.0493)\end{array}$ & $\begin{array}{c}0.528^{* * *} \\
(0.0942)\end{array}$ & $\begin{array}{c}0.504^{* * * *} \\
(0.0934)\end{array}$ & $\begin{array}{c}0.484^{\text {**** }} \\
(0.0414)\end{array}$ & $\begin{array}{c}0.547^{* * *} \\
(0.0884)\end{array}$ \\
\hline Exp_Mercosul_rest & $\begin{array}{c}-0.514^{* * *} \\
(0.0384)\end{array}$ & $\begin{array}{c}-0.380^{* * *} \\
(0.0759)\end{array}$ & $\begin{array}{c}-0.391^{* * *} \\
(0.0753)\end{array}$ & & $\begin{array}{c}-0.358^{* * *} \\
(0.0928)\end{array}$ \\
\hline Constante & $\begin{array}{c}-15.11^{* * * *} \\
(0.968)\end{array}$ & $\begin{array}{c}-32.54^{* * * *} \\
(1.826)\end{array}$ & $\begin{array}{c}-18.72^{* * *} \\
(1.805)\end{array}$ & & \\
\hline Observações & 339,021 & 339,021 & 339,021 & 349,306 & 571,448 \\
\hline $\mathrm{R}-2$ & 0.780 & 0.333 & 0.777 & 0.892 & \\
\hline Dummies de anos & Sim & Sim & Sim & Não & Sim \\
\hline EF Exp e Imp & Sim & Não & Sim & Não & Não \\
\hline EF de pares & Não & Sim & Não & Sim & Sim \\
\hline EF exp-ano & Não & Não & Não & Sim & Não \\
\hline Número de pares & & 19,056 & 19,056 & 18,441 & 19,056 \\
\hline
\end{tabular}

Tabela 3 - Estimações para a indústria

As estimações mostram um efeito robusto de criação de comércio para produtos agrícolas, pois todas os coeficientes das dummies de importações intra-Mercosul e do resto do mundo são positivos e significantes a 1\%, com exceção da dummy de desvio de comércio no modelo 5 , positiva e significante a $5 \%$. Para os modelos com as variáveis em logaritmo (1 a 4), o efeito sobre o comércio intra-bloco varia de $28 \%$ a $221 \%$, enquanto na estimação com Poisson o impacto é de $61 \%$. Nota-se também um efeito positivo e significante a $1 \%$ para as exportações agrícolas para países de fora do bloco, com exceção do modelo estimado por Poisson, em que o coeficiente é positivo mas não significante. A tabela 3 traz as estimações para o setor industrial. Os modelos estimados também são os mesmo de antes, com as importações de produtos manufaturados como variável dependente.

Assim como no caso dos produtos agrícolas, as estimações mostram um efeito robusto de criação de comércio do Mercosul sobre os produtos manufaturados, pois os coeficientes das dummies de importação intra bloco e do resto do mundo são positivos e significantes a $1 \%$, com exceção do modelo 2, em que a dummy é significante a $5 \%$. Por 
outro lado, temos nesse caso um efeito robusto de desvio de exportações em direção ao bloco, com os coeficientes dos modelos tanto em logaritmo quanto em nível negativos e significantes a $1 \%$. Os efeitos estimados do acordo sobre as exportações ao exterior vão de $-31 \%$ a $-40 \%$ para os modelos em logaritmo (1 a 4), sendo que no modelo 5 o impacto é de $-43 \%$. Portanto, apesar de não ter havido indícios de desvio de comércio na indústria, as estimações sugerem que os países do bloco redirecionaram as exportações de manufaturados para dentro deste, provavelmente em função da falta de vantagem comparativa neste setor e a incapacidade de competir em mercados externos. 



\section{Conclusão}

Os resultados obtidos evidenciam que o Mercosul ajudou a criar comércio e a aumentar as exportações para fora do bloco, sendo estes efeitos robustos a diferentes modelos, estimadores e tipos de efeitos fixos. O bloco beneficiou os países participantes, apesar dele ainda não ser uma união aduaneira completa, pois há vários produtos na lista de exceções, e de ter ocorrido tímidos avanços em termos de integração com outros blocos, em especial com a União Europeia e os países da Aliança do Pacífico. Quando se decompõe os efeitos do Mercosul sobre o comércio ao longo dos anos, nota-se que o bloco criou comércio com mais intensidade nos anos 90 e início da década passada, e desde então esse efeito vem caindo, chegando inclusive a afetar negativamente o comércio. Esse resultado indica um possível retrocesso na política comercial e maior protecionismo do bloco nos últimos anos.

Nesta dissertação também foi feito um exercício de construção de grupos contrafactuais para avaliar o que teria ocorrido com o comércio na ausência do Mercosul. O primeiro grupo construído foi para as importações que o bloco fez do resto do mundo, e ele mostra que elas seriam menores na década de 90 e maiores no começo da década passada. Já as importações intra-bloco seriam parecidas nos anos 90 e menores na década passada. Em conjunto, esses resultados sugerem um efeito maior de liberalização multilateral na primeira década do bloco e um maior protecionismo na década passada. Quando desagregamos as importações intra-bloco por países, os resultados qualitativos são muito parecidos ao caso anterior, no entanto percebe-se que os dois países menores, Paraguai e Uruguai, seriam mais afetados proporcionalmente na última década sem o Mercosul.

Outro aspecto avaliado do Mercosul foi seu impacto sobre dois setores da economia: a agricultura e a indústria. Nos dois setores tivemos evidências de criação de comércio, no entanto a agricultura usufruiu de um aumento das exportações para fora do bloco, enquanto a indústria teve desvio de exportações em direção ao bloco, o que pode indicar uma falta de competitividade neste último setor em conquistar mercados externos.

Em suma, o Mercosul surgiu em um momento no qual proliferaram a criação de 
acordos preferenciais de comércio no mundo. Concebido originalmente como uma forma de integrar a economia de seus países membros ao comércio mundial e ganhar escala tanto em mercados como em poder de negociação, o bloco perdeu um pouco de seu sentido na última década com a retomada do protecionismo. O Mercosul parece mais preocupado nos últimos anos com objetivos políticos do que comerciais, mas ele pode voltar a fazer sentido econômico com a adoção de algumas medidas, como maior abertura multilateral e acordos comerciais com outros blocos de relevância econômica. 


\section{Referências}

ADAMS, F. G. Measuring the impact of afta: An application of a linked cge system. Journal of Policy Modeling, Elsevier, v. 17, n. 4, p. 325-365, 1995. 17

ALVIM, A. M.; WAQUIL, P. D. Efeitos do acordo entre o mercosul e a união européia sobre os mercados de grãos. Revista de Economia e Sociologia Rural, SciELO Brasil, v. 43, n. 4 , p. $703-723,2005.17$

ANDERSON, J. E.; WINCOOP, E. V. Gravity with gravitas: a solution to the border puzzle. [S.l.], 2001. 10, 23

ARVIS, J.-F.; SHEPHERD, B. The poisson quasi-maximum likelihood estimator: a solution to the 'adding up'problem in gravity models. Applied Economics Letters, Taylor \& Francis, v. 20, n. 6, p. 515-519, 2013. 25

AZEVEDO, A. F. Z. d. O efeito do mercosul sobre o comércio: uma análise com o modelo gravitacional. Instituto de Pesquisa Econômica Aplicada (Ipea), 2004. 18, 36

AZEVEDO, A. F. Z. d. Mercosul: o impacto da liberalização preferencial e as perspectivas para a união aduaneira. Instituto de Pesquisa Econômica Aplicada (Ipea), 2008. 17

BACCHETTA, M. et al. A practical guide to trade policy analysis. [S.l.]: World trade organization, 2012. 23

BALDWIN, R.; TAGLIONI, D. Gravity for dummies and dummies for gravity equations. [S.l.], 2006. 23

BARCELLOS, O. Uma reflexão do comércio internacional dos setores de carne de frango e de soja do brasil e mercosul. Perspectiva Econômica, v. 2, n. 2, p. 15-36, 2006. 19

BEHAR, J. Economic integration and intra-industry trade: The case of the argentinebrazilian free trade agreement*. JCMS: Journal of Common Market Studies, Wiley Online Library, v. 29, n. 5, p. 527-552, 1991. 13

BEHAR, J. Measuring the effects of economic integration for the southern cone countries: industry simulations of trade liberalization. The Developing Economies, Wiley Online Library, v. 33, n. 1, p. 3-31, 1995. 17

BOHARA, A. K.; GAWANDE, K.; SANGUINETTI, P. Trade diversion and declining tariffs: evidence from mercosur. Journal of International Economics, Elsevier, v. 64, n. 1, p. $65-88,2004.19,20$

BRAMBILLA, I. A customs union with multinational firms: The automobile market in argentina and brazil. [S.1.], 2005. 20

BUSTOS, P. Trade liberalization, exports, and technology upgrading: Evidence on the impact of mercosur on argentinian firms. The American economic review, American Economic Association, v. 101, n. 1, p. 304-340, 2011. 13, 19

CARRERE, C. Revisiting the effects of regional trade agreements on trade flows with proper specification of the gravity model. European Economic Review, Elsevier, v. 50, n. 2, p. 223-247, 2006. 18 
CERNAT, L. Assessing regional trade arrangements: Are south-south rtas more trade diverting. Global Economy Quarterly, v. 2, n. 3, p. 235-59, 2001. 18

CHANG, W.; WINTERS, L. A. How regional blocs affect excluded countries: the price effects of mercosur. American Economic Review, World Scientific, v. 92, n. 4, p. 889-904, 2002. 19

CIPOLLINA, M.; SALVATICI, L. Reciprocal trade agreements in gravity models: A meta-analysis. Review of International Economics, Wiley Online Library, v. 18, n. 1, p. 63-80, 2010. 36

DAVID, M. B. d. A.; NONNENBERG, M. J. B. Mercosul: integração regional e o comércio de produtos agrícolas. Instituto de Pesquisa Econômica Aplicada (Ipea), 1997. 19

DEVLIN, R.; ESTEVADEORDAL, A. What's New in the New Regionalism in the Americas? [S.l.]: Bid-intal, 2001. v. 6. 9, 13

DIAO, X.; SOMWARU, A. An inquiry on general equilibrium effects of mercosur-an intertemporal world model. Journal of Policy Modeling, Elsevier, v. 22, n. 5, p. 557-588, 2000. 17

EICHER, T. S.; HENN, C.; PAPAGEORGIOU, C. Trade creation and diversion revisited: Accounting for model uncertainty and natural trading partner effects. Journal of Applied Econometrics, Wiley Online Library, v. 27, n. 2, p. 296-321, 2012. 10, 18

ETHIER, W. J. et al. Regionalism in a multilateral world. [S.1.]: World Scientific, 1998. 21

FRANCOIS, J. F.; SHIELLS, C. R. Modeling trade policy: applied general equilibrium assessments of North American free trade. [S.1.]: Cambridge University Press, 2008. 17

FREUND, C. L.; MCLAREN, J. On the dynamics of trade diversion: Evidence from four trade blocs. International Finance Working Paper, n. 637, 1999. 18, 32

GHOSH, S.; YAMARIK, S. Are regional trading arrangements trade creating?: An application of extreme bounds analysis. Journal of International Economics, Elsevier, v. 63 , n. 2, p. 369-395, 2004. 18

GHOSH, S.; YAMARIK, S. Does trade creation measure up? a reexamination of the effects of regional trading arrangements. Economics letters, Elsevier, v. 82, n. 2, p. 213-219, 2004. 18

GURGEL, Â. C.; BITENCOURT, M. B.; TEIXEIRA, E. C. Impactos dos acordos de liberalização comercial alca e mercoeuro sobre os países membros. Revista Brasileira de Economia, SciELO Brasil, v. 56, n. 2, p. 335-369, 2002. 17

HARRISON, G. W. et al. Políticas de comércio regionais, multilaterais e unilaterais do mercosul para o crescimento econômico e a redução da pobreza no brasil. Instituto de Pesquisa Econômica Aplicada (Ipea), 2003. 17

HEAD, K.; MAYER, T. Gravity equations: Workhorse, toolkit, and cookbook. CEPR Discussion Paper No. DP9322, 2013. 23, 34, 36

HEAD, K.; MAYER, T.; RIES, J. The erosion of colonial trade linkages after independence. Journal of International Economics, Elsevier, v. 81, n. 1, p. 1-14, 2010. 29 
HELPMAN, E.; MELITZ, M.; RUBINSTEIN, Y. Estimating trade flows: Trading partners and trading volumes. [S.1.], 2007. 23

KRISHNA, P. Preferential trade agreements and the world trade system: a multilateralist view. In: Globalization in an Age of Crisis: Multilateral Economic Cooperation in the Twenty-First Century. [S.1.]: University of Chicago Press, 2013. p. 131-160. 16

KRUEGER, A. O. Trade creation and trade diversion under NAFTA. [S.1.], 1999. 18

KUME, H. et al. Acordo de livre-comércio mercosul-união européia: uma estimativa dos impactos no comércio brasileiro. Instituto de Pesquisa Econômica Aplicada (Ipea), 2004. 17

LAIRD, S. Mercosur: objectives and achievements. [S.l.], 1997. 14

LIMÃO, N. Preferential trade agreements as stumbling blocks for multilateral trade liberalization: evidence for the us. CEPR Discussion Paper, 2005. 21

LIMãO, N. Preferential Trade Agreements. [S.l.], 2016. (Working Paper Series, 22138).

Disponível em: <http://www.nber.org/papers/w22138>. 14, 15, 24

MAGEE, C. S. New measures of trade creation and trade diversion. Journal of International Economics, Elsevier, v. 75, n. 2, p. 349-362, 2008. 10, 18, 32, 36

MANZETTI, L. The political economy of mercosur. Journal of Inter-American Studies and World Affairs, JSTOR, p. 101-141, 1993. 21

MARTÍNEZ-ZARZOSO, I.; NOWAK-LEHMANN, F. Augmented gravity model: An empirical application to mercosur-european union trade flows. Journal of applied economics, Universidad del CEMA, v. 6, n. 2, p. 291-316, 2003. 18

MENDES, C. C. Efeitos do mercosul no brasil: Uma visão setorial e locacional do comércio. Instituto de Pesquisa Econômica Aplicada (Ipea), 1997. 19

MORAIS, A. G. et al. Trade creation and trade diversion in mercosur and nafta. XXXIV Encontro Nacional de Economía ANPEC, Citeseer, p. 5-8, 2006. 18

MOREIRA, M. M. The mercosur that makes sense. Integration \& Trade, 2003. 16

NAGARAJAN, N.; GENERAL, I. D. MERCOSUR and trade diversion: what do the import figures tell us? [S.l.]: European Commission, 1998. 20

NEGRI, J. A. D.; ARBACHE, J. S. O impacto de um acordo entre o mercosul e a união européia sobre o potencial exportador brasileiro para o mercado europeu. Instituto de Pesquisa Econômica Aplicada (Ipea), 2003. 17

NONNEnBERG, M. J. B.; MENDOnÇA, M. J. C. d. Criação e desvio de comércio no mercosul: o caso dos produtos agrícolas. Instituto de Pesquisa Econômica Aplicada (Ipea), 1999. 10,19

OLARREAGA, M.; SOLOAGA, I. Endogenous tariff formation: the case of mercosur. The World Bank Economic Review, JSTOR, p. 297-320, 1998. 14, 19 
PIANI, G.; KUME, H. Fluxos bilaterais de comércio e blocos regionais: uma aplicação do modelo gravitacional. Instituto de Pesquisa Econômica Aplicada (Ipea), 2000. 18

PORTO, P. C.; CANUTO, O. Uma avaliação dos impactos regionais do mercosul usando dados em painel. Instituto de Pesquisa Econômica Aplicada (Ipea), 2004. 18

PORTO, S. et al. The impacts of trade facilitation measures on international trade flows. World Bank Policy Research Working Paper, n. 7367, 2015. 20

REIS, M. d.; AZEVEDO, A. F. Z. d.; LÉLIS, M. T. C. Os efeitos do novo regionalismo sobre o comércio. Estudos Econômicos (São Paulo), SciELO Brasil, v. 44, n. 2, p. 351-381, 2014. 10, 18

REIS, M. d. et al. A omc continua promovendo o comércio de forma desigual: Novas evidências a partir dos anos 1990. Revista Brasileira de Economia, SciELO Brasil, v. 69, n. 3, p. 389-404, 2015. 21

RICHARDSON, M. Endogenous protection and trade diversion. Journal of International Economics, Elsevier, v. 34, n. 3, p. 309-324, 1993. 19

ROBINSON, S.; THIERFELDER, K. Trade liberalisation and regional integration: the search for large numbers. Australian Journal of Agricultural and Resource Economics, Wiley Online Library, v. 46, n. 4, p. 585-604, 2002. 17

SILVA, J. S.; TENREYRO, S. The log of gravity. The Review of Economics and statistics, MIT Press, v. 88, n. 4, p. 641-658, 2006. 10, 24

SILVA, J. S.; TENREYRO, S. On the existence of the maximum likelihood estimates in poisson regression. Economics Letters, Elsevier, v. 107, n. 2, p. 310-312, 2010. 10

SOLOAGA, I.; WINTERSB, L. A. Regionalism in the nineties: What effect on trade? The North American Journal of Economics and Finance, Elsevier, v. 12, n. 1, p. 1-29, 2001. 10,18

SOUZA, M. J. P. d.; BURNQUIST, H. L. Facilitação de comércio e impactos sobre o comércio bilateral. Estudos Econômicos (São Paulo), SciELO Brasil, v. 41, n. 1, p. 91-118, 2011. 21

SUBRAMANIAN, A.; WEI, S.-J. The wto promotes trade, strongly but unevenly. Journal of international Economics, Elsevier, v. 72, n. 1, p. 151-175, 2007. 21

TINBERGEN, J. et al. Shaping the world economy; suggestions for an international economic policy. Books (Jan Tinbergen), Twentieth Century Fund, New York, 1962. 23

VASCONCELOS, C. R. F. Criação e desvio de comércio: Análise do fluxo comercial entre o brasil e o mercosul para alguns produtos industrializados. Análise Econômica, v. 19, n. $36,2000.19$

VASCONCELOS, C. R. F. O comércio brasil-mercosul na década de 90: uma análise pela ótica do comércio intra-indústria. Revista Brasileira de Economia, SciELO Brasil, v. 57, n. 1 , p. 283-313, 2003. 19

VENABLES, A. Regionalism and economic development. New Frontiers in Development: Policies and Institutions for Trade and Regional Integration, Citeseer, 2002. 15, 16 
VENABLES, A. J. Winners and losers from regional integration agreements*. The Economic Journal, Wiley Online Library, v. 113, n. 490, p. 747-761, 2003. 15

VINER, J. The customs union. New York, 1950. 16

WILSON, J. S.; MANN, C. L.; OTSUKI, T. Assessing the benefits of trade facilitation: A global perspective. The World Economy, Wiley Online Library, v. 28, n. 6, p. 841-871, 2005. 21

YEATS, A. J. Does mercosur's trade performance raise concerns about the effects of regional trade arrangements? The World Bank Economic Review, World Bank, v. 12, n. 1, p. $1-28,1998.10,20$ 



\section{Apêndice}

Abaixo estão as estimações com a dinâmica do Mercosul:

\begin{tabular}{|c|c|c|}
\hline Variáveis & $\begin{array}{c}(1) \\
\text { Efeitos fixos } \\
\text { Log de imports }\end{array}$ & $\begin{array}{c}(2) \\
\text { Efeitos fixos } \\
\text { Log de imports }\end{array}$ \\
\hline Log imp PIB & $\begin{array}{c}0.857^{* * *} \\
(0.0213)\end{array}$ & $\begin{array}{c}0.839 * * * \\
(0.0112)\end{array}$ \\
\hline Log exp PIB & $\begin{array}{c}0.555^{* * *} \\
(0.0223)\end{array}$ & \\
\hline Log imp pop & $\begin{array}{c}0.773^{* * *} \\
(0.0672)\end{array}$ & $\begin{array}{c}0.725^{* * *} \\
(0.0294)\end{array}$ \\
\hline Log exp pop & $\begin{array}{c}-0.300^{* * *} \\
(0.0762)\end{array}$ & \\
\hline Intra Mercosul & $\begin{array}{l}0.195^{*} \\
(0.114)\end{array}$ & $\begin{array}{c}0.579^{* * *} \\
(0.174)\end{array}$ \\
\hline intra_mercosul1991 & $\begin{array}{c}-0.276^{* * *} \\
(0.0773)\end{array}$ & $\begin{array}{c}-0.539^{* *} \\
(0.223)\end{array}$ \\
\hline intra_mercosul1992 & & $\begin{array}{l}-0.324 \\
(0.215)\end{array}$ \\
\hline intra_mercosul1993 & $\begin{array}{c}0.0888 \\
(0.0799)\end{array}$ & \\
\hline intra_mercosul1994 & $\begin{array}{c}0.103 \\
(0.0929)\end{array}$ & $\begin{array}{c}0.105 \\
(0.232)\end{array}$ \\
\hline intra_mercosul1995 & $\begin{array}{l}0.0384 \\
(0.112)\end{array}$ & $\begin{array}{r}-0.0219 \\
(0.203)\end{array}$ \\
\hline intra_mercosul1996 & $\begin{array}{l}0.224^{*} \\
(0.132)\end{array}$ & $\begin{array}{c}0.199 \\
(0.188)\end{array}$ \\
\hline intra_mercosul1997 & $\begin{array}{c}0.177 \\
(0.149)\end{array}$ & $\begin{array}{c}0.192 \\
(0.204)\end{array}$ \\
\hline intra_mercosul1998 & $\begin{array}{l}0.0965 \\
(0.165)\end{array}$ & $\begin{array}{c}0.236 \\
(0.216)\end{array}$ \\
\hline intra_mercosul1999 & $\begin{array}{l}0.0814 \\
(0.163)\end{array}$ & $\begin{array}{c}0.157 \\
(0.207)\end{array}$ \\
\hline intra_mercosul2000 & $\begin{array}{c}0.209 \\
(0.167)\end{array}$ & $\begin{array}{l}0.360^{*} \\
(0.202)\end{array}$ \\
\hline intra_mercosul2001 & $\begin{array}{c}0.245 \\
(0.170)\end{array}$ & $\begin{array}{l}0.0630 \\
(0.196)\end{array}$ \\
\hline intra_mercosul2002 & $\begin{array}{c}0.569^{* * *} \\
(0.212)\end{array}$ & $\begin{array}{r}-0.0638 \\
(0.224)\end{array}$ \\
\hline intra_mercosul2003 & $\begin{array}{c}0.663^{* * *} \\
(0.184)\end{array}$ & $\begin{array}{l}0.0154 \\
(0.212)\end{array}$ \\
\hline intra_mercosul2004 & $\begin{array}{c}0.589^{* * *} \\
(0.183)\end{array}$ & $\begin{array}{l}-0.362^{*} \\
(0.202)\end{array}$ \\
\hline intra_mercosul2005 & $\begin{array}{c}0.510^{* * *} \\
(0.181)\end{array}$ & $\begin{array}{c}-0.433^{* *} \\
(0.212)\end{array}$ \\
\hline intra_mercosul2006 & $\begin{array}{c}0.390^{* *} \\
(0.197)\end{array}$ & $\begin{array}{c}-0.458^{* *} \\
(0.214)\end{array}$ \\
\hline intra_mercosul2007 & $\begin{array}{l}0.389^{*} \\
(0.212)\end{array}$ & $\begin{array}{l}-0.452^{*} \\
(0.240)\end{array}$ \\
\hline intra_mercosul2008 & $\begin{array}{l}0.399^{*} \\
(0.232)\end{array}$ & $\begin{array}{l}-0.460 * \\
(0.250)\end{array}$ \\
\hline intra_mercosul2009 & $\begin{array}{c}0.280 \\
(0.190)\end{array}$ & $\begin{array}{c}-0.604^{* * *} \\
(0.234)\end{array}$ \\
\hline intra_mercosul2010 & $\begin{array}{c}0.166 \\
(0.172)\end{array}$ & $\begin{array}{c}-0.644^{* * *} \\
(0.215)\end{array}$ \\
\hline
\end{tabular}




\begin{tabular}{|c|c|c|}
\hline \multirow[t]{2}{*}{ intra_mercosul2011 } & 0.0532 & $-0.822^{* * *}$ \\
\hline & $(0.178)$ & $(0.236)$ \\
\hline \multirow[t]{2}{*}{ intra_mercosul2012 } & -0.0239 & $-0.805^{* * *}$ \\
\hline & $(0.161)$ & $(0.207)$ \\
\hline \multirow[t]{2}{*}{ intra_mercosul2013 } & -0.0533 & $-0.870^{* * *}$ \\
\hline & $(0.170)$ & $(0.220)$ \\
\hline \multirow[t]{2}{*}{ intra_mercosul2014 } & -0.0704 & $-0.688 * * *$ \\
\hline & $(0.161)$ & $(0.215)$ \\
\hline \multirow[t]{2}{*}{ Imp_Mercosul_rest } & $0.281 * * *$ & $0.288^{* * *}$ \\
\hline & $(0.102)$ & $(0.0979)$ \\
\hline \multirow[t]{2}{*}{ imp_mercosul_rest1992 } & -0.00212 & -0.0335 \\
\hline & $(0.104)$ & $(0.125)$ \\
\hline \multirow[t]{2}{*}{ imp_mercosul_rest1993 } & 0.177 & 0.102 \\
\hline & $(0.123)$ & $(0.129)$ \\
\hline \multirow[t]{2}{*}{ imp_mercosul_rest1994 } & 0.176 & 0.0931 \\
\hline & $(0.123)$ & $(0.127)$ \\
\hline \multirow[t]{2}{*}{ imp_mercosul_rest1995 } & $0.207^{*}$ & 0.173 \\
\hline & $(0.107)$ & $(0.119)$ \\
\hline \multirow[t]{2}{*}{ imp_mercosul_rest1996 } & $0.252^{* *}$ & $0.212^{*}$ \\
\hline & $(0.112)$ & $(0.113)$ \\
\hline \multirow[t]{2}{*}{ imp_mercosul_rest1997 } & $0.225^{*}$ & 0.179 \\
\hline & $(0.123)$ & $(0.121)$ \\
\hline \multirow[t]{2}{*}{ imp_mercosul_rest1998 } & 0.180 & 0.145 \\
\hline & $(0.111)$ & $(0.112)$ \\
\hline \multirow[t]{2}{*}{ imp_mercosul_rest1999 } & 0.0951 & 0.0683 \\
\hline & $(0.118)$ & $(0.114)$ \\
\hline \multirow[t]{2}{*}{ imp_mercosul_rest 2000} & $0.249 * *$ & 0.186 \\
\hline & $(0.121)$ & $(0.120)$ \\
\hline \multirow[t]{2}{*}{ imp_mercosul_rest 2001} & 0.0193 & -0.0386 \\
\hline & $(0.128)$ & $(0.124)$ \\
\hline \multirow[t]{2}{*}{ imp_mercosul_rest 2002} & -0.183 & $-0.235^{*}$ \\
\hline & $(0.133)$ & $(0.123)$ \\
\hline \multirow[t]{2}{*}{ imp_mercosul_rest 2003} & $-0.229^{*}$ & $-0.284^{* *}$ \\
\hline & $(0.138)$ & $(0.124)$ \\
\hline \multirow[t]{2}{*}{ imp_mercosul_rest2004 } & -0.119 & -0.154 \\
\hline & $(0.137)$ & $(0.120)$ \\
\hline imp_mercosul_rest2005 & -0.137 & -0.188 \\
\hline & $(0.143)$ & $(0.126)$ \\
\hline imp_mercosul_rest2006 & 0.0448 & -0.0248 \\
\hline & $(0.132)$ & $(0.118)$ \\
\hline imp_mercosul_rest 2007 & -0.0226 & -0.0822 \\
\hline & $(0.133)$ & $(0.121)$ \\
\hline imp_mercosul_rest2008 & -0.0316 & -0.0908 \\
\hline & $(0.142)$ & $(0.126)$ \\
\hline imp_mercosul_rest2009 & -0.126 & $-0.212^{*}$ \\
\hline & $(0.142)$ & $(0.125)$ \\
\hline imp_mercosul_rest2010 & 0.147 & 0.0549 \\
\hline & $(0.139)$ & $(0.120)$ \\
\hline imp_mercosul_rest 2011 & $0.274^{* *}$ & $0.210^{*}$ \\
\hline & $(0.132)$ & $(0.117)$ \\
\hline imp_mercosul_rest 2012 & 0.212 & 0.154 \\
\hline & $(0.137)$ & $(0.121)$ \\
\hline imp_mercosul_rest2013 & 0.129 & 0.0681 \\
\hline & $(0.138)$ & $(0.123)$ \\
\hline imp_mercosul_rest2014 & $0.310^{* *}$ & $0.212^{*}$ \\
\hline & $(0.133)$ & $(0.116)$ \\
\hline Exp_Mercosul_rest & $-0.195^{* *}$ & \\
\hline & $(0.0913)$ & \\
\hline exp_mercosul_rest1991 & 0.147 & \\
\hline & $(0.0908)$ & \\
\hline
\end{tabular}




\begin{tabular}{|c|c|c|}
\hline exp_mercosul_rest1992 & $\begin{array}{c}0.219^{* * *} \\
(0.0677)\end{array}$ & \\
\hline exp_mercosul_rest1994 & $\begin{array}{c}-0.103 \\
(0.0811)\end{array}$ & \\
\hline exp_mercosul_rest1995 & $\begin{array}{l}-0.0629 \\
(0.0951)\end{array}$ & \\
\hline exp_mercosul_rest1996 & $\begin{array}{l}-0.0696 \\
(0.0897)\end{array}$ & \\
\hline exp_mercosul_rest1997 & $\begin{array}{c}-0.105 \\
(0.0944)\end{array}$ & \\
\hline exp_mercosul_rest1998 & $\begin{array}{c}-0.208 * * \\
(0.0976)\end{array}$ & \\
\hline exp_mercosul_rest1999 & $\begin{array}{c}-0.151 \\
(0.0927)\end{array}$ & \\
\hline exp_mercosul_rest2000 & $\begin{array}{l}-0.241 * * \\
(0.0993)\end{array}$ & \\
\hline exp_mercosul_rest 2001 & $\begin{array}{c}0.0734 \\
(0.0970)\end{array}$ & \\
\hline exp_mercosul_rest 2002 & $\begin{array}{c}0.534 * * * \\
(0.0990)\end{array}$ & \\
\hline exp_mercosul_rest2003 & $\begin{array}{c}0.533^{* * *} \\
(0.107)\end{array}$ & \\
\hline exp_mercosul_rest 2004 & $\begin{array}{c}0.819 * * * \\
(0.103)\end{array}$ & \\
\hline exp_mercosul_rest 2005 & $\begin{array}{c}0.818^{* * *} \\
(0.103)\end{array}$ & \\
\hline exp_mercosul_rest2006 & $\begin{array}{c}0.722^{* * *} \\
(0.100)\end{array}$ & \\
\hline exp_mercosul_rest 2007 & $\begin{array}{c}0.721 * * * \\
(0.106)\end{array}$ & \\
\hline exp_mercosul_rest 2008 & $\begin{array}{c}0.731 * * * \\
(0.106)\end{array}$ & \\
\hline exp_mercosul_rest2009 & $\begin{array}{c}0.755^{* * *} \\
(0.111)\end{array}$ & \\
\hline exp_mercosul_rest 2010 & $\begin{array}{c}0.663 * * * \\
(0.107)\end{array}$ & \\
\hline exp_mercosul_rest 2011 & $\begin{array}{c}0.725^{* * *} \\
(0.111)\end{array}$ & \\
\hline exp_mercosul_rest 2012 & $\begin{array}{c}0.644^{* * *} \\
(0.113)\end{array}$ & \\
\hline exp_mercosul_rest 2013 & $\begin{array}{c}0.665^{* * *} \\
(0.111)\end{array}$ & \\
\hline exp_mercosul_rest 2014 & $\begin{array}{c}0.467^{* * *} \\
(0.121)\end{array}$ & \\
\hline Constante & $\begin{array}{c}-34.02^{* * *} \\
(1.754)\end{array}$ & \\
\hline Observações & 364,055 & 375,893 \\
\hline $\mathrm{R}-2$ & 0.337 & 0.878 \\
\hline Dummies de anos & $\operatorname{Sim}$ & Não \\
\hline EF Exp e Imp & Não & Não \\
\hline EF de pares & $\operatorname{Sim}$ & Sim \\
\hline EF exp-ano & Não & Sim \\
\hline Número de pares & 19,306 & 18,825 \\
\hline
\end{tabular}

Tabela 4 - Dinâmica do Mercosul 


\begin{tabular}{|c|c|c|c|c|}
\hline \multicolumn{5}{|c|}{ Lista de países } \\
\hline Afeganistão & Chipre & Guatemala & Malásia & República Central Africana \\
\hline África do Sul & Colômbia & Guiana & Malauí & República Checa \\
\hline Albânia & Congo & Guiné & Máli & República Dominicana \\
\hline Alemanha & Coréia do Sul & Guiné-Bissau & Marrocos & Ruanda \\
\hline Angola & Costa do Marfim & Haiti & Maurícius & Rússia \\
\hline Arábia Saudita & Costa Rica & Holanda & Mauritânia & Senegal \\
\hline Argélia & Croácia & Honduras & México & Serra Leoa \\
\hline Argentina & Cuba & Hong Kong & Mianmar & Síria \\
\hline Armênia & Dinamarca & Hungria & Moçambique & Somália \\
\hline Austrália & Egito & Iêmen & Moldávia & Sri Lanka \\
\hline Áustria & El Salvador & Índia & Montenegro & Suazilândia \\
\hline Azerbaijão & Emirados Árabes Unidos & Indonésia & Namíbia & Sudão \\
\hline Bangladesh & Equador & Irã & Nepal & Suécia \\
\hline Belarus & Eritréia & Iraque & Nicarágua & Suíça \\
\hline Bélgica & Eslováquia & Irlanda & Níger & Tailândia \\
\hline Benin & Eslovênia & Israel & Nigéria & Tajiquistão \\
\hline Bolívia & Espanha & Itália & Noruega & Tanzânia \\
\hline Bósnia e Herzegovina & Estados Unidos & Jamaica & Nova Zelândia & Togo \\
\hline Botswana & Estônia & Japão & Omã & Trinidad e Tobago \\
\hline Brasil & Etiópia & Jordânia & Panamá & Tunísia \\
\hline Bulgária & Fiji & Kuwait & Papua Nova Guiné & Turcomenistão \\
\hline Burkina Faso & Filipinas & Latvia & Paquistão & Turquia \\
\hline Burundi & Finlândia & Lesoto & Paraguai & Ucrânia \\
\hline Camarões & França & Líbano & Perú & Uganda \\
\hline Camboja & Gabão & Libéria & Polônia & Uruguai \\
\hline Canadá & Gâmbia & Líbia & Portugal & Venezuela \\
\hline Casaquistão & Gana & Lituânia & Quênia & Vietnã \\
\hline Chade & Geórgia & Macedônia & Quirguistão & Zâmbia \\
\hline Chile & Grécia & Madagascar & Reino Unido & Zimbábue \\
\hline China & & & & \\
\hline
\end{tabular}

Tabela 5 - Amostra de países 